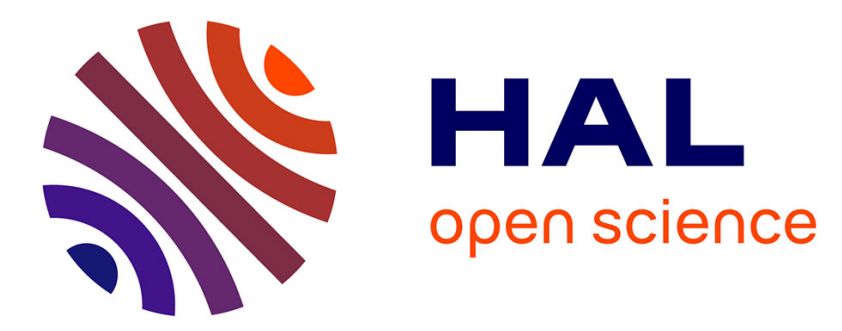

\title{
Pour une chronologie des arcs de triomphe de Gaule Narbonnaise (à propos de l'arc de Glanum) \\ Pierre Gros
}

\section{To cite this version:}

Pierre Gros. Pour une chronologie des arcs de triomphe de Gaule Narbonnaise (à propos de l'arc de Glanum). Gallia - Fouilles et monuments archéologiques en France métropolitaine, 1979, 37 (1), pp.55-83. 10.3406/galia.1979.1595 . hal-01935500

\section{HAL Id: hal-01935500 https://hal.science/hal-01935500}

Submitted on 16 Jun 2020

HAL is a multi-disciplinary open access archive for the deposit and dissemination of scientific research documents, whether they are published or not. The documents may come from teaching and research institutions in France or abroad, or from public or private research centers.
L'archive ouverte pluridisciplinaire HAL, est destinée au dépôt et à la diffusion de documents scientifiques de niveau recherche, publiés ou non, émanant des établissements d'enseignement et de recherche français ou étrangers, des laboratoires publics ou privés.

\section{(ㅇ)(1) $\$$}

Distributed under a Creative Commons Attribution - NonCommercial - NoDerivatives $\mid 4.0$ 


\title{
POUR UNE CHRONOLOGIE DES ARCS DE TRIOMPHE DE GAULE NARBONNAISE
}

\section{(à propos de l'arc de Glanum)}

\author{
par Pierre GROS
}

La récente monographie sur l'are de Gilanum a mis à la disposition des historiens un dossier de dessins at de photographies dont le caractère exhaustif et l'extrème précision autorisent des observations de tout ordre'. Après les deux volumes consacres au monument d'Orange ${ }^{2}$, ce nouveau livre apporte une contribution essentielle à la connaissance d'une série unique en son genre, celle des ares de triomphe de Gaule Narbonnaise.

Le moment semble venu diune enquète globale sur les partis monumentaux dont res édifices sont tributaires, et sur le détail de leur ornementation non figurée. Jusqu'à présent l'analyse de ces aspects proprement architecturaux, pourtant décisifs quant à l'atablissement d'une chronologie relative, est restée presque absente du débat : pas plus ¿ Orange qu'à Glanum les problèmes de typologie et de modénature n'ont été abordés de front, si bien que les références de base demeurent en ce domaine des enquêtes systématiques déja anciennes ${ }^{3}$. ou des travaux plus analytiques. mais qui ne concernent pas directement la Narbonnaiset.

On peut certes comprendre les raisons d'une telle lacune : l'importance des décors histories est telle, sur ces monuments, qu'elle focalise l'attention des spécialistes. Ine théorie récente justifie presque la concentration exclusive de l'intérêt et de la recherche sur les éléments figurés, en désignant les ares sud-galliques comme les supports d'un programme ironographique : derriere leur message symbolique, of l'idéologie triomphaliste dont ils sont porteurs. sefficerait en quelque sorte leur ordonnance arrhitecturales.

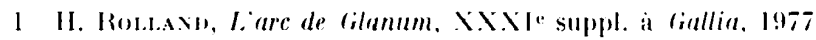

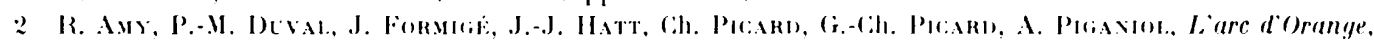
Xi"suppl, à ciallia, 196:2.

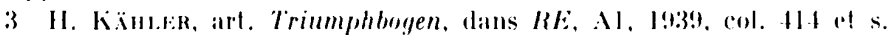

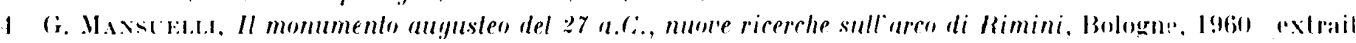
de . Irte antica e moderna, $x$, 1959 a d 9,1960 .

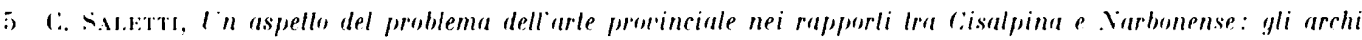

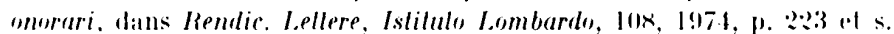


Cette ordonnanee, pourtant, est signifiante. Lamplitude des variations concernant les dates de construction se réduirait sensiblement si lon y pretait attention. Sans parler de la polémique suscitée naguère par le regretle P. Mingazani à propos de l'arc d'orangre. ret pour nous en tenir à celui de Glanum. les hypothoses proposeses restent varies. al peu contraignantes. Ene tradition tenace, qui remonte peut-être a M. Cilere, situe cel edlifice a l'origine de la série. et le désigne, parfois sans autre prexcision, comme l'are le plus ancien de la Province ; lobe implicite est ici quon ne saurail dissocier la construction de l'are de reble du mausolee des Julii, avec lequel il a fini par constituer, pour une simple raison de voisinage, une sorte de groupe unitaire ${ }^{8}$. Pour les auteurs qui ont voulu proposer une chronologie plus précise, les dates seechelonnent depuis le troisième quart du zer s. al. .J.-Ci.. jusquà l’époque liberienne, en passant par diverses etapes intermédiaires. dont la première décennie du regene d'Augustro.

Beaucoup de ces propositions ne reposent pas sur une analyse interne du momument. mais cherchent à en caler la construction à un moment jugé convenable, étant entendu quiun are de triomphe, surtout s’il est orne de frises d’armes ef de trophés. romme ceux de Carpentras. de Gilanum et d’Orange. se doit d’être lié à une victoire ou à une conquêtore.

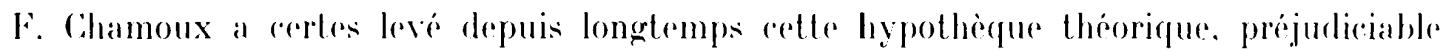
a une saine approche du probleme. en rappelant que l’implantation de tels édifices ne sacerorhait pas forément à une opération militaire poneluelle, mais pouvail revelir, dans les provinces ocedentales, une signiliadion beauroup plus large.e. Mais la tentation reste vive de rapporter aux epoques troublées du sereond triumviral ou du début rlu resene d'Auguste les images de bataille ou de soumission qui constituent apparemment l'essentiel de leur discours ireonographique.

In examen des aaractères structurels oblige d'abord a remettre en question less schémas crolutifs traditionnels. Mème nuancéses romme celles de H. Kähler. les typologies systematiques, dans la mesure où, par definition et par vocation, elles prorèalent du simple au rompliqué. tendent à imposer löidée diune nette posteriorite des ares à trois

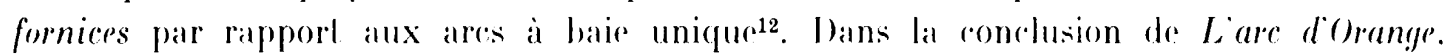

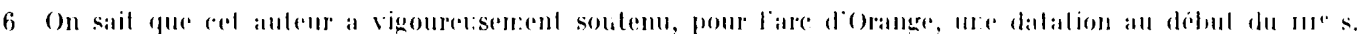

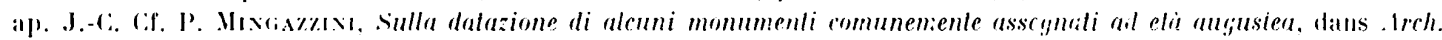

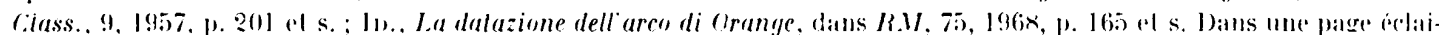

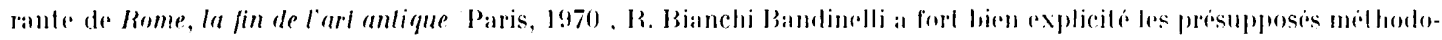

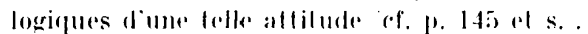

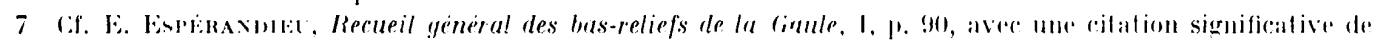

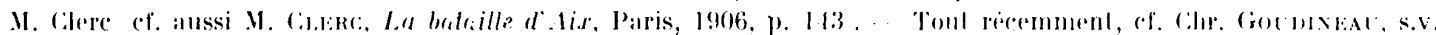

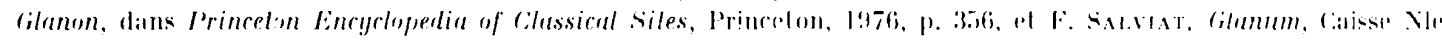

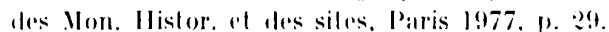

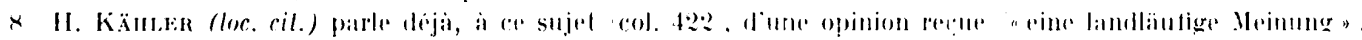

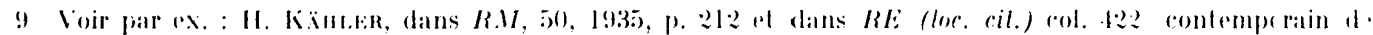

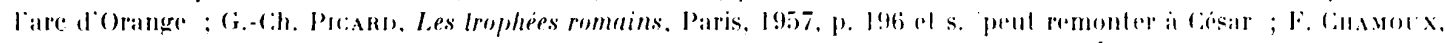

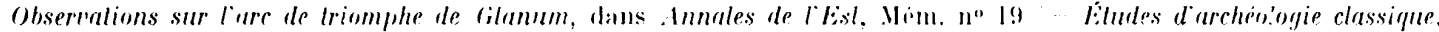

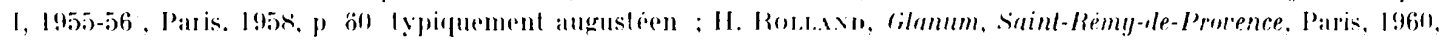

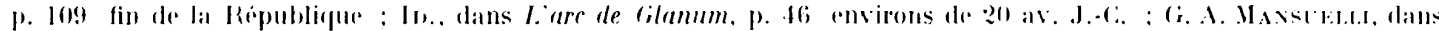

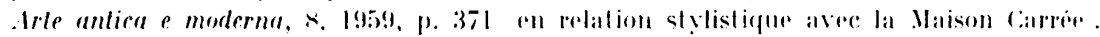

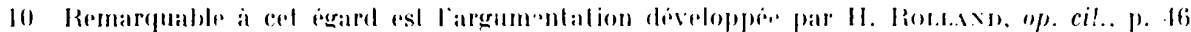

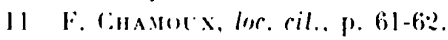

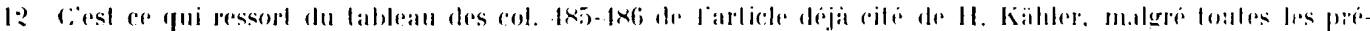
caulions prises par cet anteur dans le cours de ses developerements. 


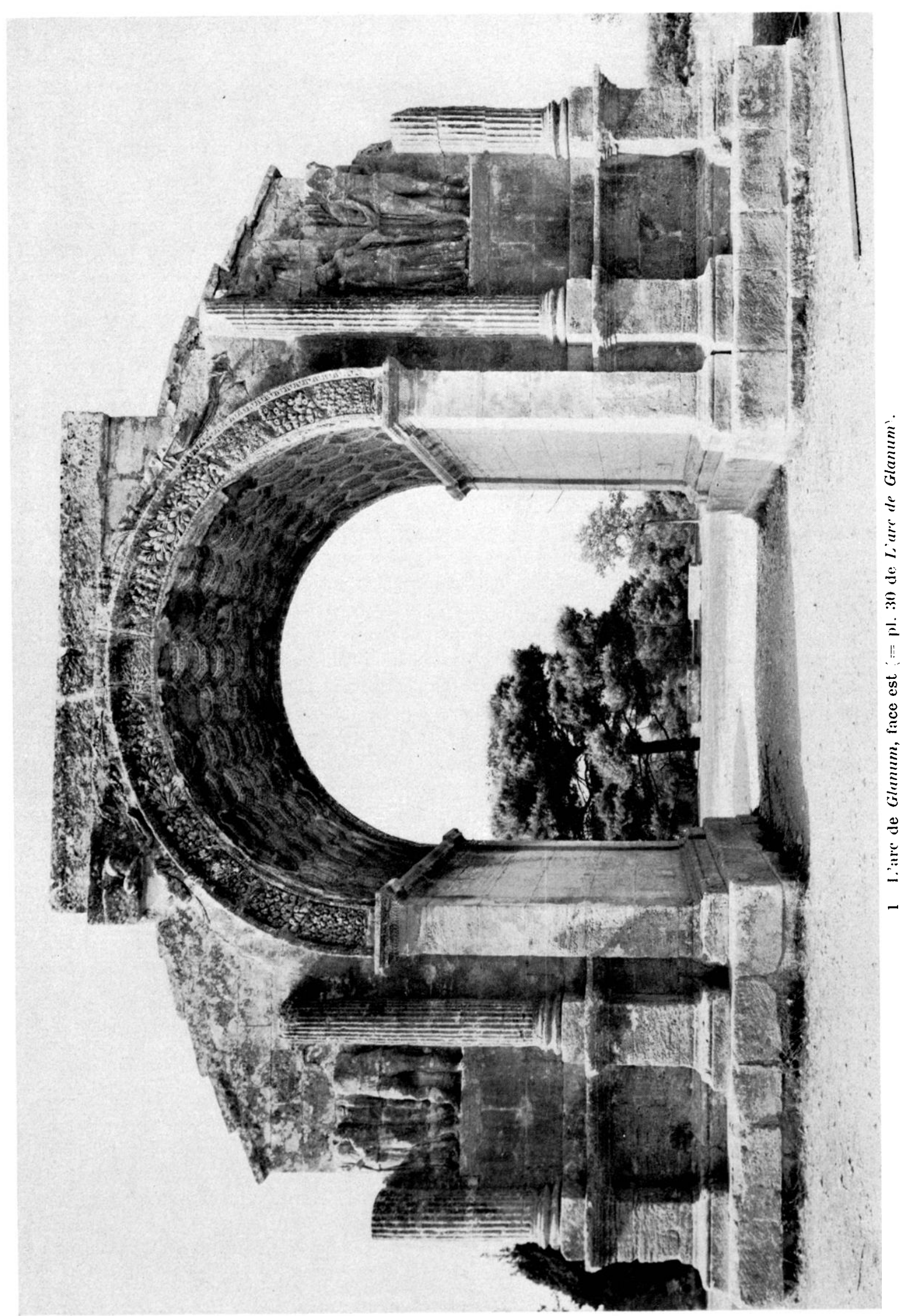


P.-.I. Duval a ouvert la voie à une meilleure comprehension du parti architectural en montrant qu'on ne saurait définir cet édifice comme le produit d'une complication progressive du plan à un seul fornix ${ }^{13}$. Nous ne partageons pas pour autant l'opinion de G. Mansuelli. qui entend établir un lien direct entre les ares d'Aoste. de Vérone at de Gilanum ${ }^{14}$.

Le caractere le plus remarquable de la série sud-gallique lient en ellet dans le rapport triss parliculier qu'entretient l'arcade centrale atvec les piles latérales, percées ou non de baies serondaires. Si l'on excepte le tétrapyle de Cavaillon, qui semblait répondre à des intentions dilférentes, il apparait qu'aux ar's de Carpentras, de (ilanum et d'Orange les pilast res sur lesquels repose l'arcaade descendent jusqu'au niveau du sol antique, oi ils se lerminent par une base moulurée el une plinthe (figr. 1). Ce détail n'est pas sans importance, car il délinil le ròle de la structure courbe dans la syntaxe des laces principales. Au contraire de ce qui se produit a Aoste ou l'arcade. par ailleurs tris large, repose sur des pilastres courts, élevés sur un podium trapu régnant sur toute la base de l'édifice, la disposition adoptée en Xarbonnaise crée une discontinuité entre les supports de l'arcus et les demi-colonnes d'encadrement. Ces dernieres en effet reposent sur des piédestaux saillants qui s'élevent jusqu'au tiers environ de la hauteur des pilastres. Les colonnes s'affirment ainsi comme des éléments de haut relief. dont la fonction est d'animer les surfaces qui encadrent te fornix central, mais non pas de souligner la structure d'ensemble de l'édifice. Ce phénoméne est. particulièrement sensible à (i'anum. où les colonnes délimitent plastiquement. pour les meltre en valeur, les reliefs latéraux ${ }^{15}$; mais la mème constatation vaut pour Orange, où les amas d'armes "suspendus" au-dessus des passages secondaires revètent autant d'importance, dans la conception générale, que les ouvertures elles-mèmes, el surgissent d'un champ vigoureusement cerné par les colonnes engagées ${ }^{16}$. Ie programme iconographique est d'ailleurs réparli de la même facon sur les deux monuments : au centre, avec les guirlandes de l'archivolte. les thimes de l'abondance millinariste el de la paix; de part et d'autre. ater les Iropheses et les armes, le thime de la conquete et de la soumission.

C'est en rela que les ares de (ilamum el d'Orange sont profondément semblables, el quéen mime temps ils se distinguent des édifices de Ciaule Cisialpine ou d'ltalie du nord, auxquels on les a souvent comparés : a Aoste el à Vérone. les colonnes engagées ont pour fonction de cantonner et de limiter un volume qui reste essentiellement unitaire ${ }^{17}$; les deux colonnes rentrales sont tangentes a l'archivolte et mìme a Aoste elles en absorbent les retombées; les colonnes extrèmes soulignent l'angle des piles; enfin elles partent du mème niveau que les pilastres de la baie (fig. 2). I Gilanum, le fail que les colonnes centrales ne soient pas contiguës à la baie, atteste la volonté de définir sur les piles un espace relativement indépendant, qui peut dis lors se développer selon ses normes propres, et en particulier, au prix d'un élargissement peu imporlant. se creuser d'ouvertures a son tour. On ne doil donc pas admeltre la lentative de réduction de H. Kähler, qui raméne

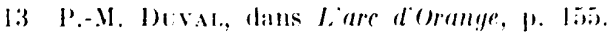

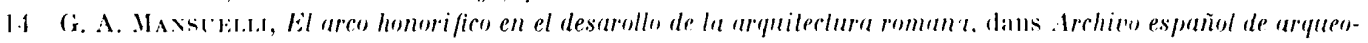

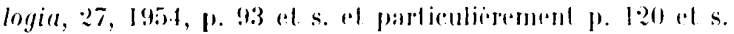

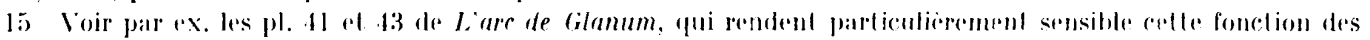
colonnes.

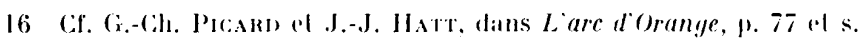

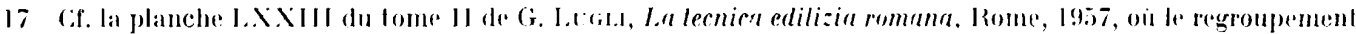

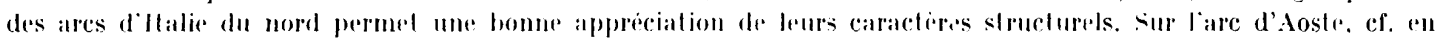

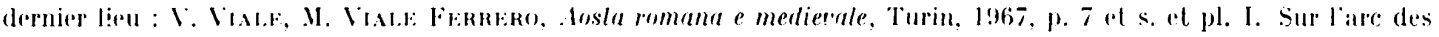

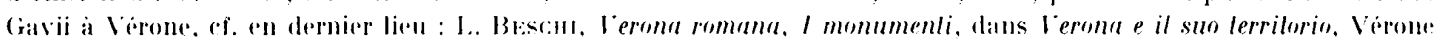

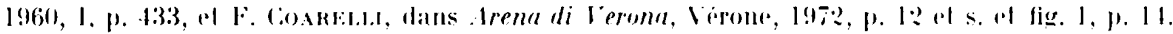




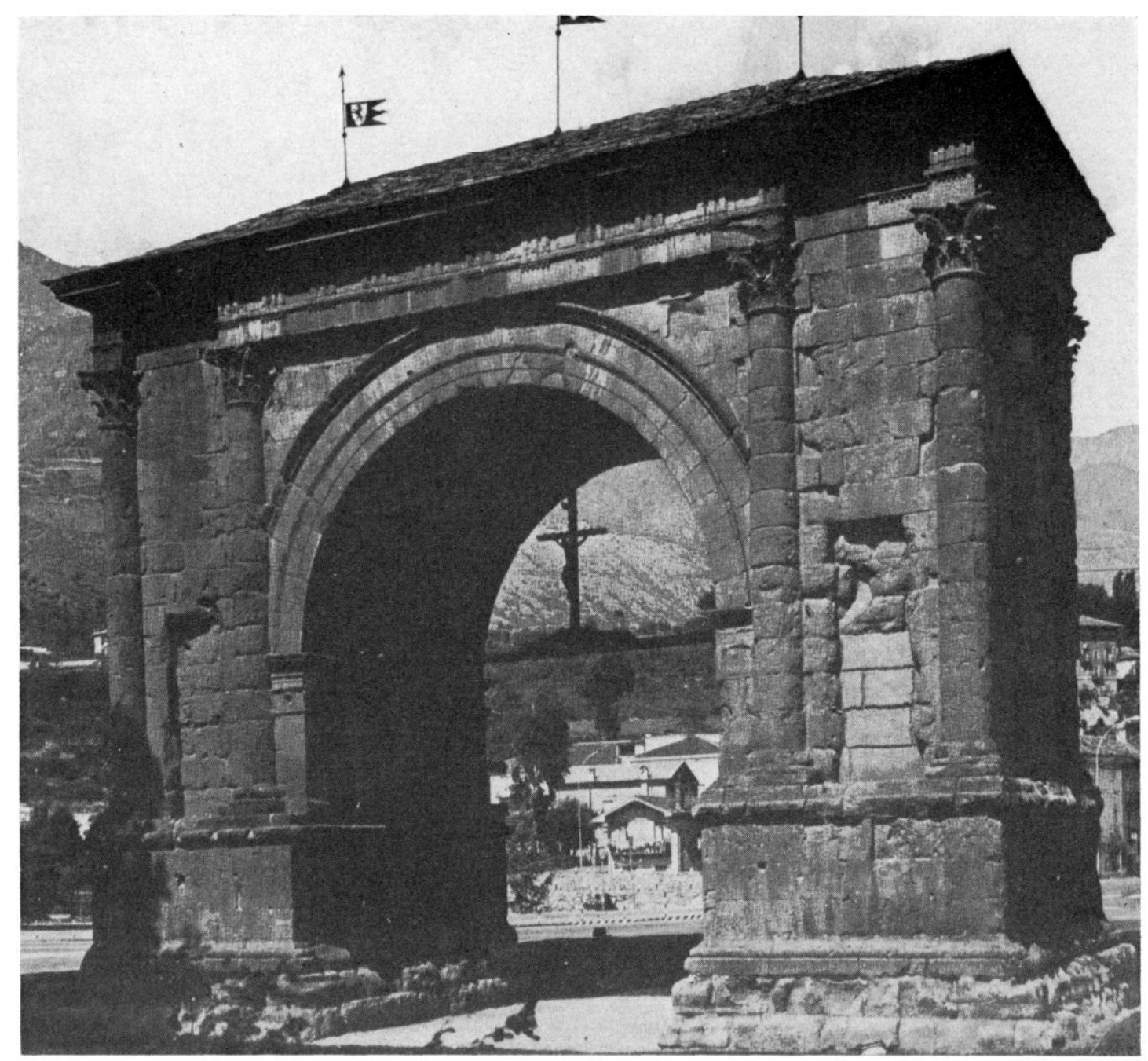

$\because$ L'are d'Aoste.

le schéma glanique au type II b de sa typologie, lequel comporte des colonnes tangentes aux reins de l'archivolte ${ }^{18}$.

Cette indépendance des composantes ne nuit pas à l'unité de l'ensemble, dans la mesure où les trames de base, aux arcs de Glanum et d'Orange, attestent un réel souci d'intégration : à Glanum, J. Bruchet a montré que le plan se composait de "triangles égyptiens», et que les points de croisement des hypoténuses définissaient l'axe des pilastres des pilastres et non pas des colonnes, nouvelle preuve du caractère non structurel de ces dernières ${ }^{19}$ (fig. 3). A Orange, le décrochement de l'entablement vers l'arrière, au-dessus des petits arcs, ainsi que le fronton central, au-dessus du grand arc, tendent a accuser, dans les parties hautes, le rôle plastique de l'encadrement de la baie principale, et à dissocier les colonnes centrales des colonnes d'angle ${ }^{20}$; mais cette recherche ne se traduit nullement au niveau du plan, où l'on relève une trame comparable à celle de Glanum,

I8 H. KäHt.er, loc. cit., col. 484.

19 J. Brucher, op. cit., p. 47 et pl. $2 x$.

20 K. Ams, dans L'arc d'Orange, p. 22 , $\mathrm{s}$. 


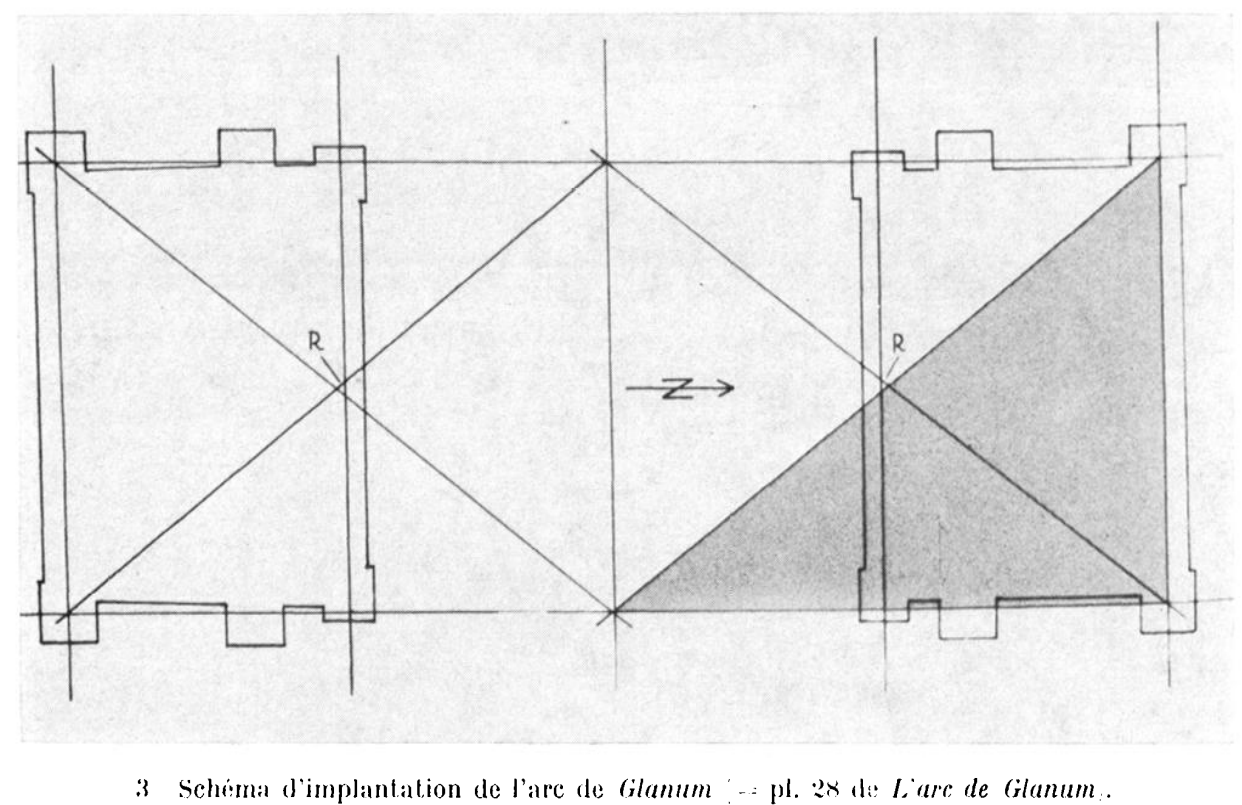

malgré les contraintes nées de la réulilisalion d'une fondation préexistantę21. Én cela les créations sud-galliques marquent un net progres par rapport à celles de la Rome tardo-républicaine ou protoaugustéenne; si l'on ne sait rien de la Porla Trigemina, les restitutions proposées de l'arc parthique du Forum nous mettent en présence d'une composilion non orqanique, ou les éléments latéraux, simples édicules surajoutés, se contentent de flanquer un arc à un seul fornix ${ }^{22}$ : le schéma tripartite se cherche encore, en 19 av. J.-G., sans déboucher sur une solution salisfaisante, mème si déja rertains thèmes celui des victoires dans les écoingons de l'arcature centrale, par exemple ont trouvé leur expression et leur position canoniques ${ }^{23}$.

La dissocialion plastique, que nous avons soulignée entre l'arcade el les ordres engagés, est confirmée, en Narbonnaise, par la position de l'archivolte, qui est rarement hangente a l'architrave. Cela permet à l'extrados de présenter éventuellement un tracé irrégulier, qui facilite son insertion dans l'appareil de la façade. Mais dans la plupart des cas cette particularité struclurelle est dissimulée par le fait que la courbure de la zone décorée n'occupe que la partie inférieure des claveaux, créant ainsi, pour l'observateur situé au pied du monument, l'impression d'une arcade rigoureusement extradossée ${ }^{24}$.

Il y a là une dissociation d'un autre type, qui intervient cetle fois entre le support construit et son ornement. Elle est observable aux arcs de Glanum, de Cavaillon, d'Orange et de Carpentras; pour ce dernier, seule la face sud est concernée, et c'est la partie supérieure des claveaux qui porte le décor (fig. 4). On ignore semblable disposition aux arcs d'Aoste, de Suse et de Vérone. Si la porte d'Auguste a Rimini et l'are des sergii a Pola présentent une caractéristique comparable, c'est sous une forme moins sensible, puisque le décor de l'archivolte n'y revêt que l'aspect traditionnel d'une

21 [1., p. 57 et s., pl. 11 .

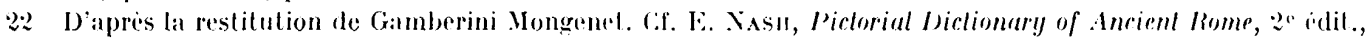
1968, II, fig. 100 at P. Zaxksk, Forum Romanum, Rome, 197:2, p. 15 at fig. 21.

23 le claveau oi est seupter la victoire de l'ecoinçon ganche de l'arc parthique est reproduit par P. Zaxkro, op. cit., fig. 19. La siluation des victoires sur les ares de Cavaillon et dorange pest lros certainement inspirée de ce prestigrieux prócedent.

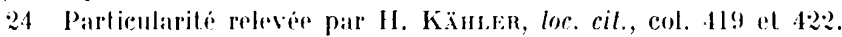




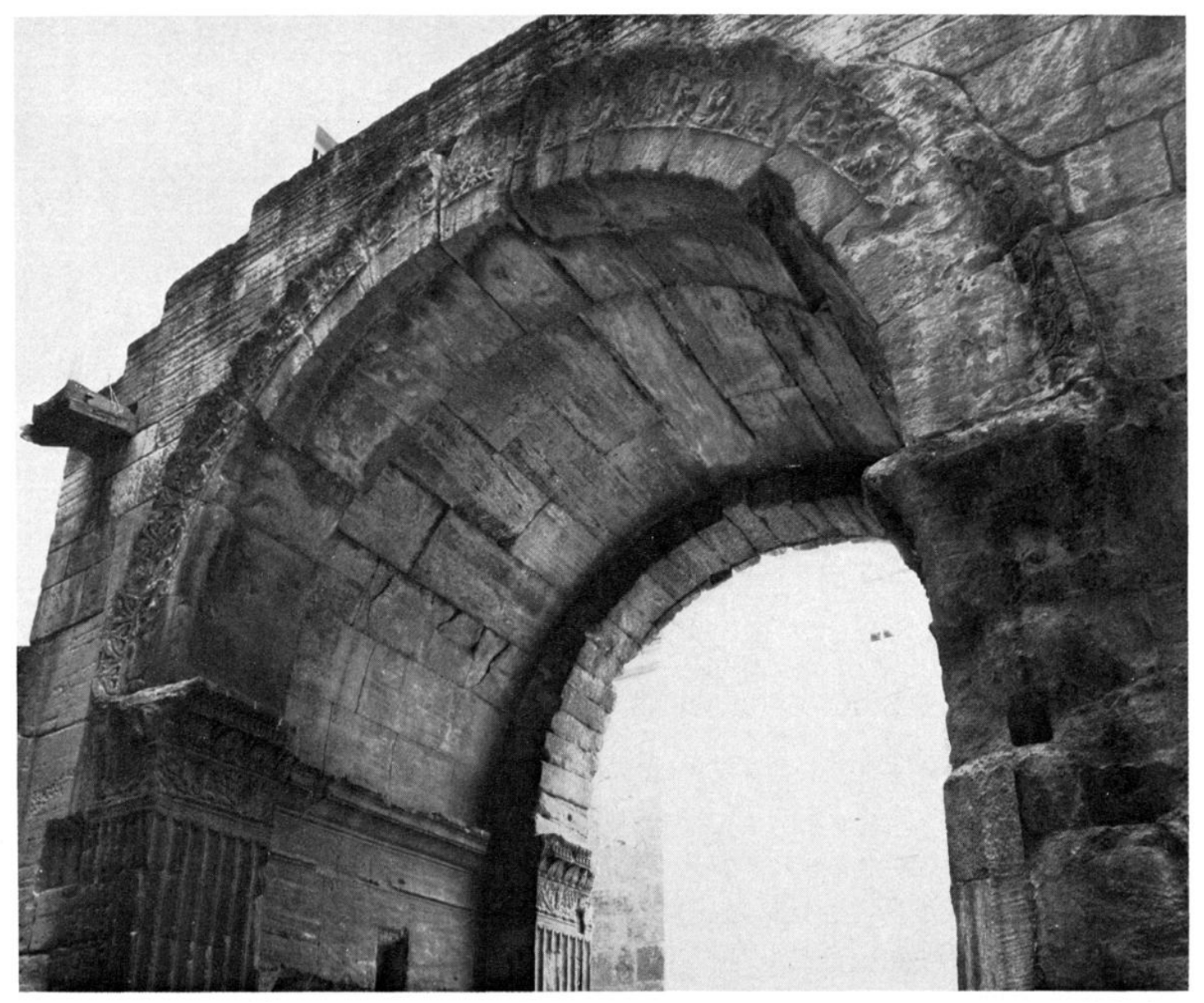

4 Fine sud de l'are de Ciarpentras.

architrave a fasciae, avec un couronnement discret ${ }^{25}$. En Narbonnaise, l'ornementation de la face antérieure de l'arc est au contraire d'une grande richesse : faite de rinceaux ou de guirlandes, elle s'achive par des couronnements complexes où dominent les oves (Orange), les rais de cœur (Glanum, Gavaillon, Garpentras) ou mème les modillons plats (arc du Rhòne à Arles) ${ }^{26}$.

Trois autres constantes meritent d'ètre releveses, dans l'organisation de l'arcature des monuments sud-galliques. C'est d'abord l'alsence presque générale d'une clé de faile, qui se distinguerait des autres voussoirs par son volume, ou par le relief plus accusé de son décor ${ }^{27}$. Mème lorsque l'un des culots générateurs du rinceau se situe au sommet de l'archivolte, comme sur la face sud de l'arc de Carpentras, la continuité plastique n'est pas rompue par une saillie de la pierre. C'est lá un élément d'apprécialion chronologique : on imagine mal un arc monumental sans clé saillante aux

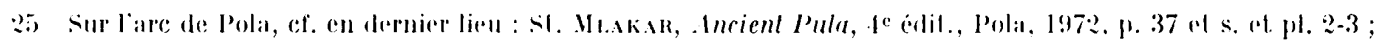

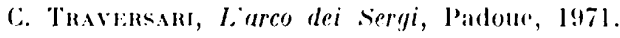

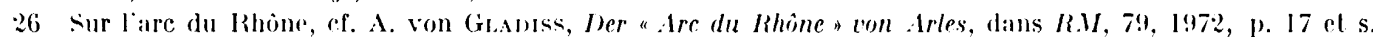
(excellente monographe sur ee monument dispartu, dale avere raison du debut du regne diugusle; certaines series

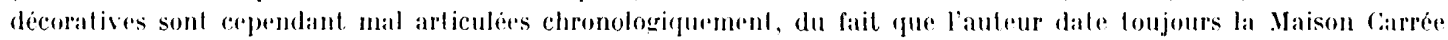
do l'avant-derniere decennic du er s. av. J.-C., cf. p. 71,

27 C.f. F. Chanotx, loc. cit., 1. 57. 


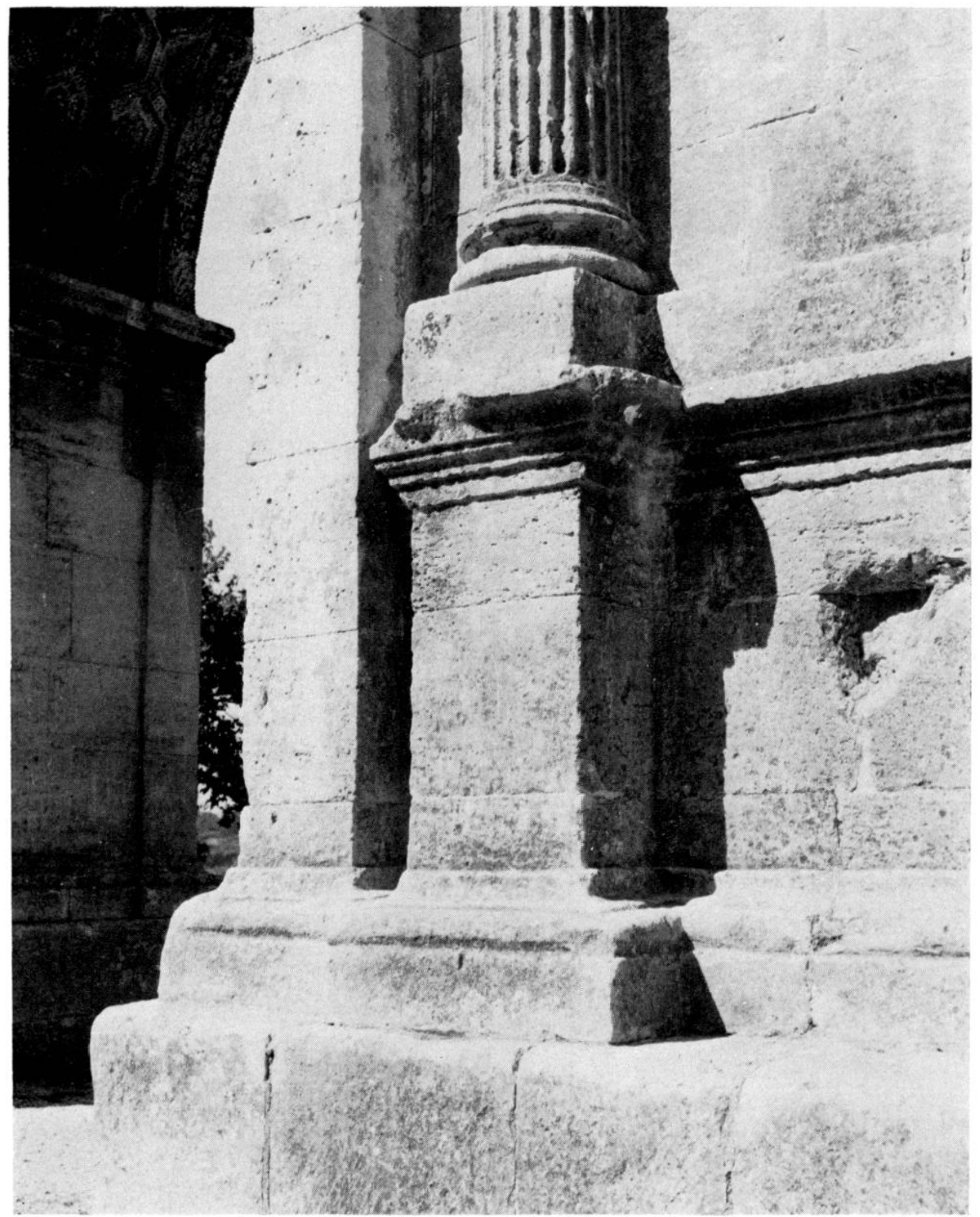

5 Face est, pile nord de l'arc de cilanum = pl. 39, $\because$ de Liare de Glantam.

époques flavienne, antonine ou sévérienne ${ }^{28}$. I ces seuls exemples d'une mise en valeur du faite de l'arc se rencontrent à Arles, où les dessins de Sautereau, sujets à caution comme beaucoup de croquis anciens, restituent une clé porteuse d'une tète radiée ${ }^{29}$, et au quadrifrons du mausolée de Glanum, où le relief de la Méduse est plus fort que celui des rinceaux ${ }^{30}$.

En second lieu, les archivoltes ne reposent jamais sur de véritables chapiteaux de pilastres,

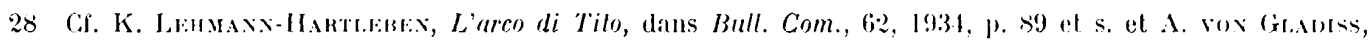
loc. cil., p. इ3.

29 Cf. A. vox Gianiss, loc. cil., p. 52 et s., pli. 36.

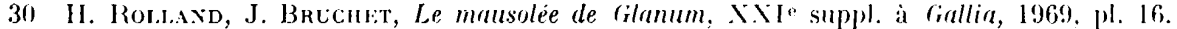


comme à l'arc de Šuse, par exemple, mais sur des impostes richement profilées, dont la modénature, sinon le décor, se poursuit le long de la paroi interne du fornix.

Enfin, aux arcs de Gilanum et d'Orange, ainsi quau tétrapyle de Gavaillon, la voûte des baies est tout entiere revêtue de caissons; ce raffinement, inconnu à Loste, Rimini et Suse, confirme le role pródominant réservé, en Gaule Narbonnaise, à la structure courbe, el a sa fonclion de lieu de passage 31.

Il ressort de cette breve recension des caracteres spécifiques de la série sud-gallique une certaine unite de conception. Au sein de ce groupe relativement homogine se trouve réaffirmér, par des voles différentes de celles de H. Kähler ${ }^{32}$, l'etroite parenté des monuments de Gilanum at d'Orange. Il convient maintenant de préciser la date de construction de ces deux ares, el cela non pas en fonction de donnés indirectess, fournies par lohistoire on l'epigraphice, mais a partir dobservations stylistiques, les seules qui, replacees dans des series, permettent la définition d'une "fourchette chronologique directement applicable aux edifiers en question. Ensuite nous essaierons de placer, par rapport au jalon ainsi défini. les ares de Ciraillon et de Carpentras, pour lesquels nous possédons également un dossier photographique complet ${ }^{33}$.

Notre tentalive beneficie du fait, relativement récent, que l'on dispose désormais de deux pivots importants. pour l'articulation d'une chronologie relative des décors architecturaux du début de l'Empire en Gaule Narbonnaise. Grâce aux etudes de G.Ch. Picard ${ }^{34}$ et de F. Kleiner ${ }^{35}$, la date du mausolée de Glanum paraît bien assurée : sa construction se situe selon toute vraisemblance dans les années 30-20 av. J.-C.

D'autre part l'analyse de la modénalure de la Maison Carrée de Nîmes nous a permis d'acquérir la conviction que ce temple avait été concu et réalisé à la fin de la dernière décennie du $\mathrm{I}^{\mathrm{er}}$ s. av. J.- (. avec, pour la finition de certains ornamenta, un débordement dans les premières années de notre èréc.

A réfaut des chapiteaux corinthiens, disparus avec l'entablement et l'attique, on peut tirer parti, pour l'arc de Glanum, des moulures de base et de couronnement des piédestaux, du profil de la base attique, du décor des impostes, de celui de l'archivolte et des douelles, enfin des caissons de la voute. Il n'est certes pas facile, comme le souligne, W. D. Ineilmeyer, de dégagrer de ces modénatures secondaires, dont l'histoire reste à écrire, des conclusions chronologiques indiscutables ${ }^{37}$.

On retiendra malgré tout les indices suivants, qui nous paraissent décisifs : au couronnement des piédestaux, la lourde cyma reversa ne règne plus (fig. 5 el 6). Cette moulure

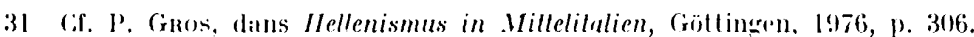

$3: 2$ Loc. ril., col. $42: 2$.

33 Dossier constitue par le lahoratoire photographigue du dentre Camille Jullian d'Aix-en-Provence.

31 G.-Ch. Prcann, Gilanum el les origines de l'arl romano-protencal, dans Giallia, :21, 1967, p. 118 at s. 'four-

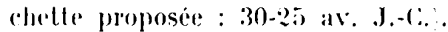

35) F. KIFINER, Artists in the Roman World. An ilinerant Worlishop in Auguslan Ganl, dans .Melanges darch.

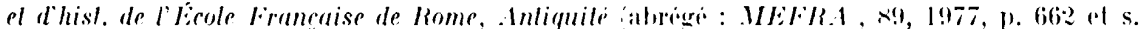

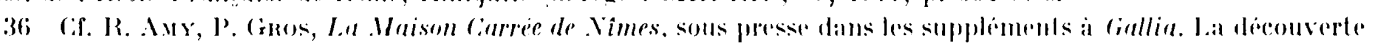

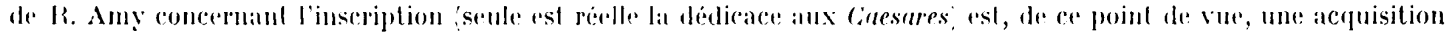

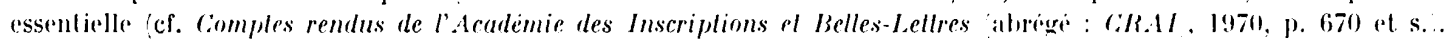

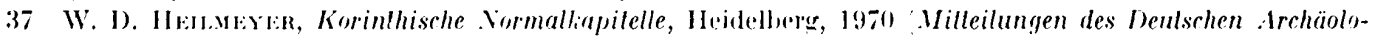
gischen Instiluts: WIHA, Ergänzungsheft 16, p. 114. 

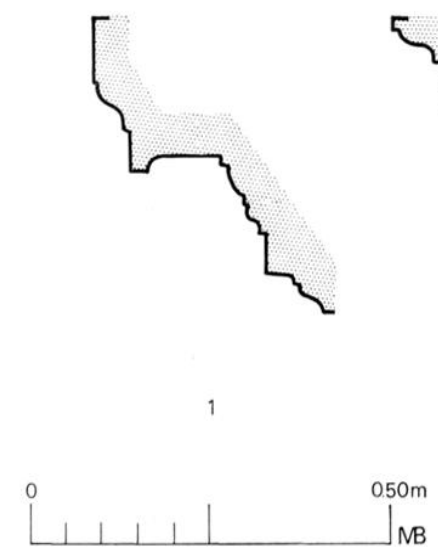

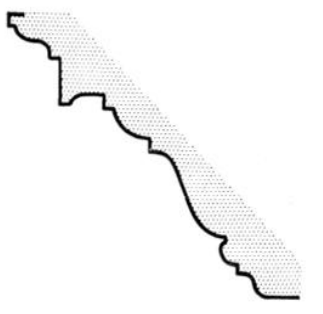

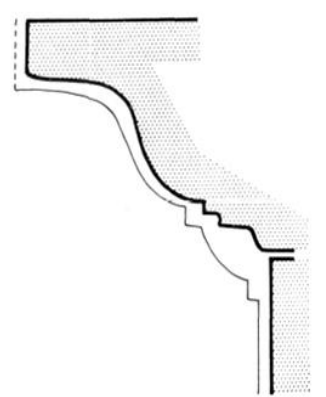

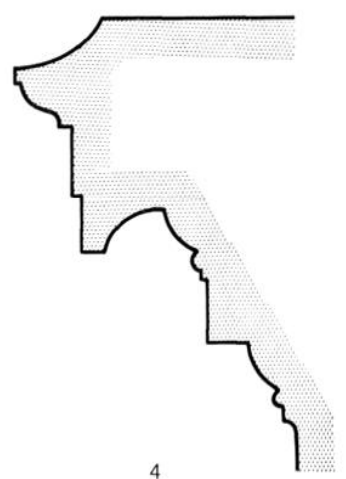

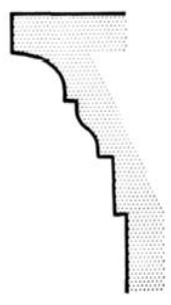

5

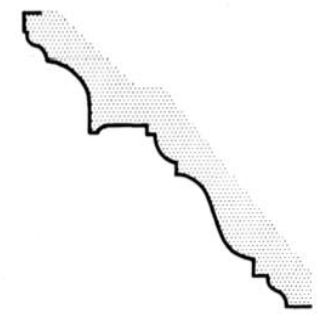

6

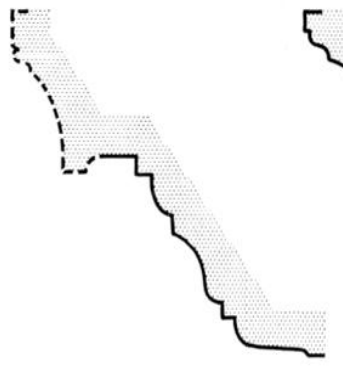

7

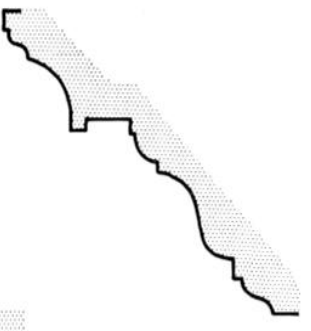

8

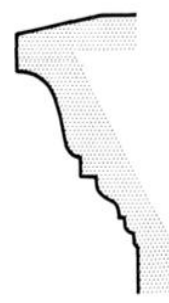

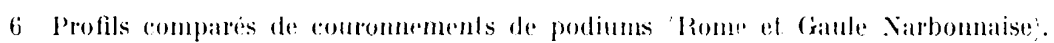

Rome

1 Temple reclangulaire du frorum Bostrum

2 Temple de Císar divinise

3 Trimple B du Largo Argentina secondr phase

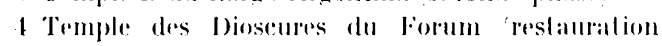
liberientre
Gault: Narbonnaise

5) Are de filamum

(6) Xymphice de Nimes

T Temple: d'oramge

S Maison liarrec de Nimes

9) Are do()range.

dont L. T. Shoe a montré qu'elle cédait progressivement la place à la doucine droite, à Rome et en Italie, dès la fin du ${ }_{1}{ }^{\mathrm{e}}$ s. ar. J.-C., se maintient en Gaule Narbonnaise jusqu'au début de l'époque augustéenne, comme le prouve encore sa présence à la base du podium des temples géminés ${ }^{38}$ (fig. 8). Le seul fait qu'elle ait disparu de l'ornementation de l'are est déjà, en soi, un signe important d'évolution, qui exclut une datation césarienne ou triumvirale, at dissocie résolument cet édifice du mausolée voisin, où le socle du quadrifrons et celui de la tholos présentent exclusivement de vigoureuses doucines renversées ${ }^{39}$.

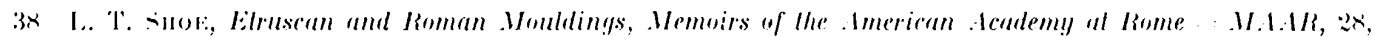

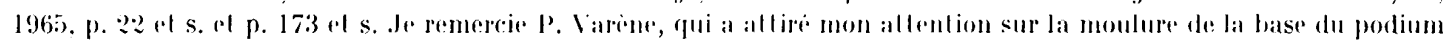

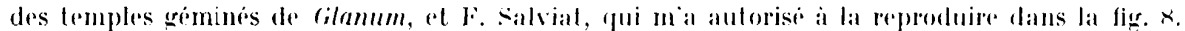

39 Cif. Le mausolie de Cilanum, pl. 9 a pl. 19. 


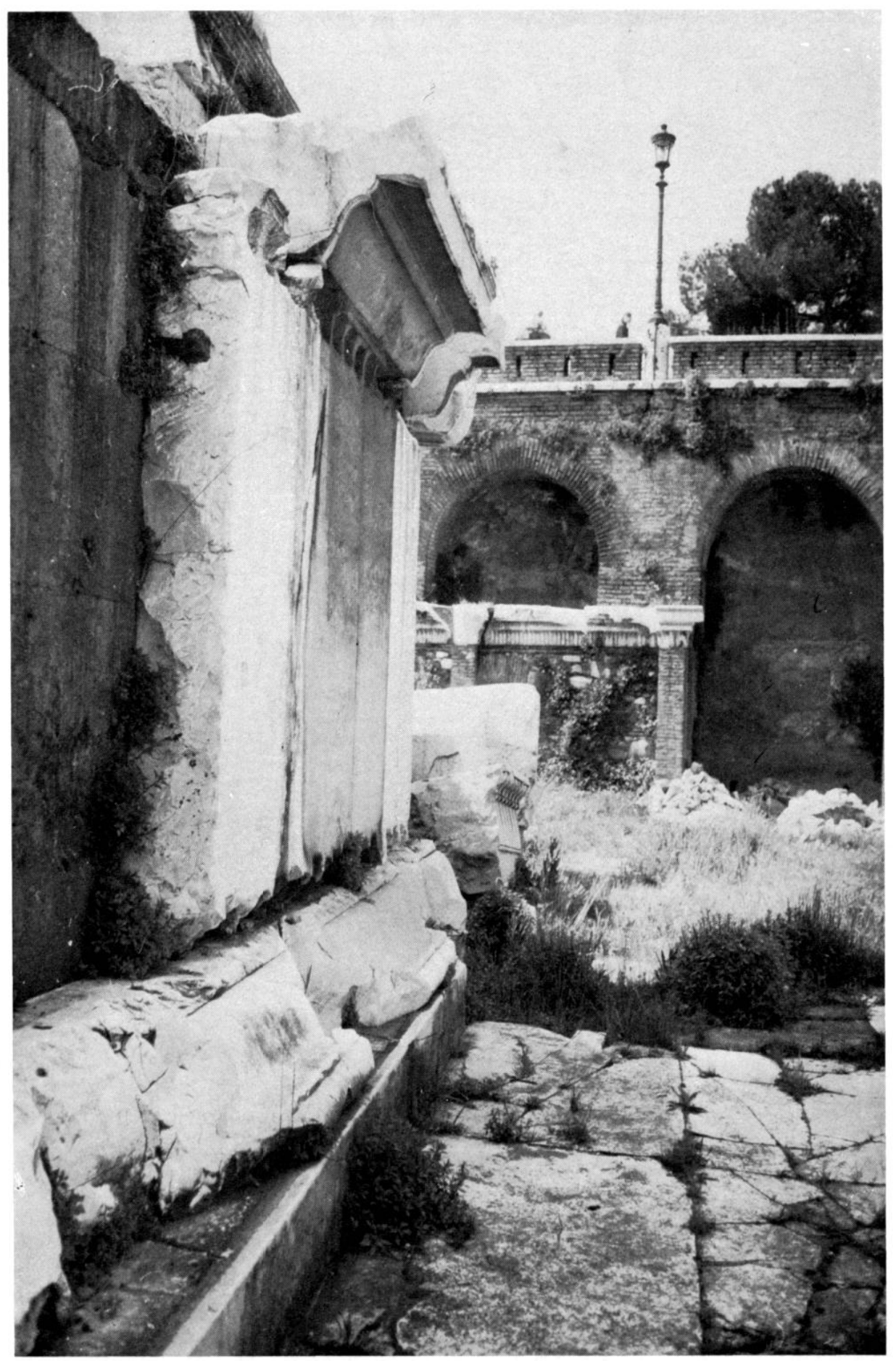

7 Podium du lemple de Mars Ellor a liome. 

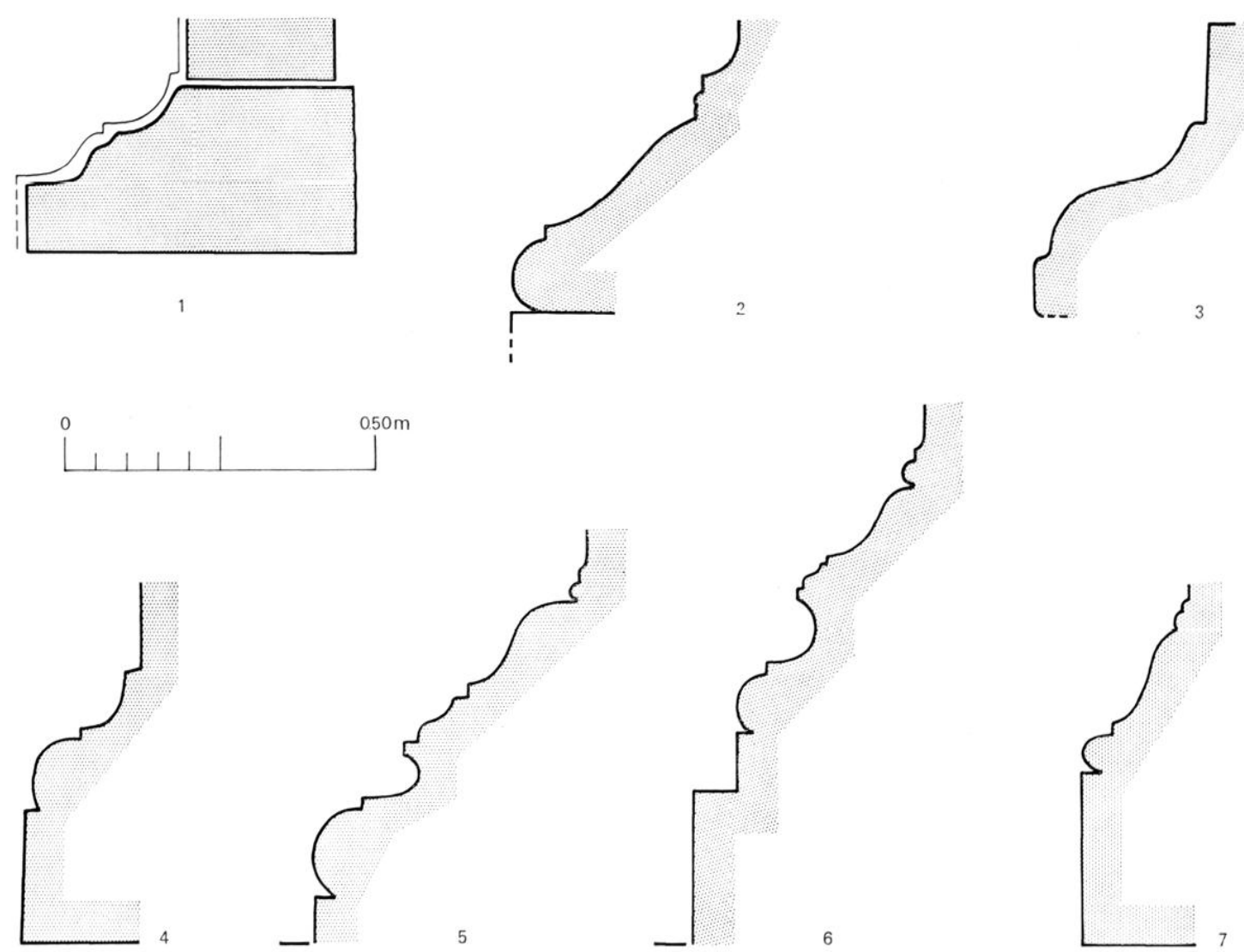

$x$ Profils comparés de bases de podiums liome et Gaule Narbonnaise,

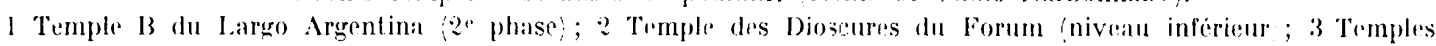

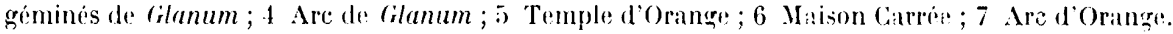

Sans doute, la séquence légère qui, sur l'arc, remplace celles-ci, ne laisse aucune place à la cyma recta, puisqu'elle comporte, de bas en haut, une baguette, un petit talon de transition et un congé; cependant les décorateurs du monument n'ignoraient pas la doucine droite, à laquelle ils recourent sur la moulure saillante où s'appuient les reliefs latéraux ${ }^{40}$. De surcroît, on retrouve, à la base des piédestaux, au-dessus de la plinthe, le tore unique, caractéristique, à Rome, des podiums des temples médio-augustéens ${ }^{41}$ (fig. 7 et 8).

Pour la base des colonnes de l'are de Glanum, il convient d'abord de faire justice d'une idée répandue par H. Rolland, selon laquelle elle aurait été dépourvue de plinthe : "Il est de règle à Glanum, écrit cet auteur, pour les monuments d'époque hellénistique, que le premier tore des bases repose directement sur un stylobate; et l'on ne manquera pas à cette occasion de se référer à l'exemple donné par les bases du quadrifrons du mausolée voisis ${ }^{42}$. " La comparaison est évidemment fallacieuse. S'il est vrai que les bases du quadrifrons reposent sans plinthe sur leur stylobate quadrangulaire, celles de l'arc s'appuient sur des assises saillantes, destinées à les isoler du sominet des

40 Ci. L'arc de Glanum, pl. 22 à 25.

41 On le trouve en effet an temple de .lars C.ttor et des Dioscures. Ci. infra, p. 73.

4.2 II. Rolmavo, L'arc de Glanum, p. 19. 


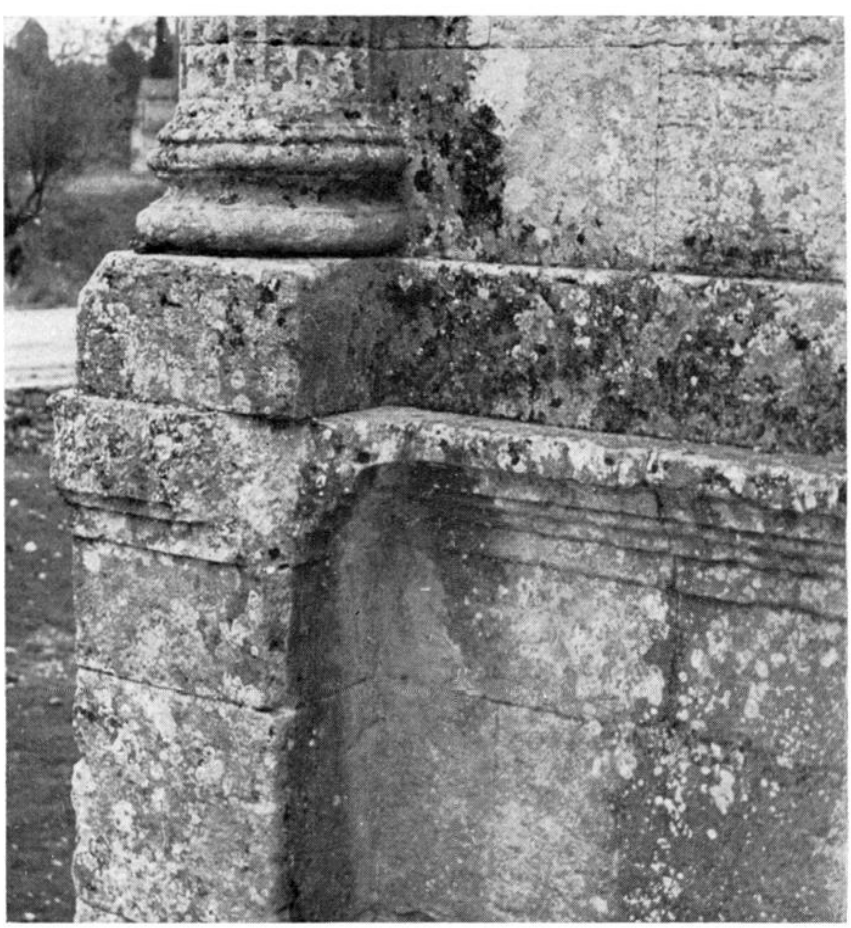

9 Face ouest, extremite nord de laare de cilanum la plinthe et la base de lordre engage $=$ pl. 40, 2 de L'arc de filanum.

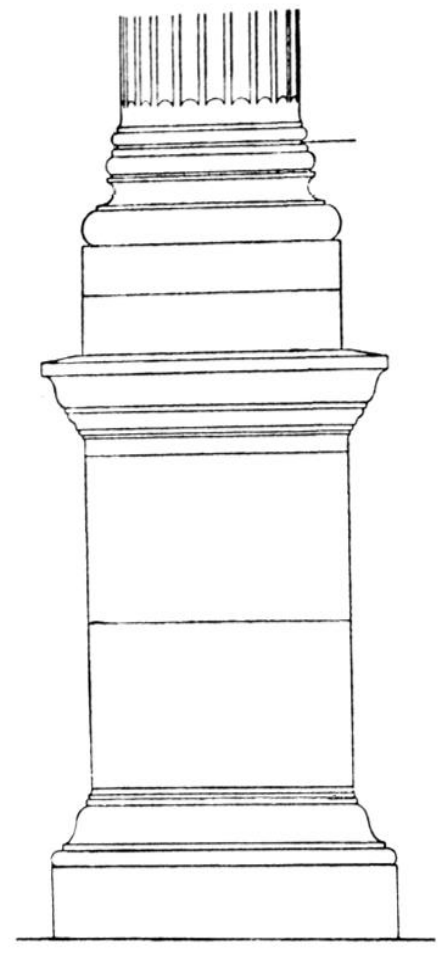

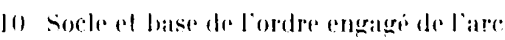
d'oramge :-: figr. : de L'are dorange'.

piédestaux ${ }^{43}$ (figr. 9). Sans doute, la hauteur de ces assises paraill-elle démesurée par rapport à celle des bases elles-mêmes, et l'on hésiterait à y chercher la trace d'une plinthe, si l'arc d'Orange ne venait à notre secours : on y observe en effet la mème disposition, avec un progrès dans la lisibilité, puisqu'un joint horizontal sépare cette fois ce qui appartient encore au socle de ce qui doit être considéré comme la base de la colonne (fig. 10). Ce joint fait défaut à Glanum, mais il n'en faut pas moins admeltre que la plinthe des bases est intégrée à cette assise saillante. Et l'on se souviendra que les bases atliques ne sont communément pourvues de plinthes, en milieu italien ou occidental, qu'à partir des années 20-15 av. J.-G., au plus tiot ${ }^{44}$.

De toute façon le profil de la base des colonnes avec sa scotie profonde et parabolique, plus haute que le plus gros des deux tores, est de toute évidence d'époque augustéenne avancée : en

43 (if. Ie mausolée, pl. 12 ol s. (pour le quadrifrons) et pl. 19 pour la tholos . Voir en revanche L'arc, pl. 6-7, 39-40, etc. Pour refuser a l'assise sous-jacente aux bases de l'are le statut de plinthe, H. Folland alligue 'p. 19, comme un argument décisif le fait que cette assise se délache aussi en légere saillie sur la base des murs antre les colonnes. Cela constitue en réalite la meilleure confirmation de notre interprétation : ladite assise étail concue par l'architecte comme partie integrante de l'ordre et, selon le schéma couramment adopté dans les trmples pseudo-périptéres (voir la Yaison Carrée, la modenature de la hase des colonnes de l'ordre engagé se poursuit en écho, comme an pied des orthostates d'une cella. S'il s'agissait, comme le veut H. Rolland, d'une "assise de couronnement du podium ", on ne comprendrait plus une telle disposition.

Dans le locabulaire de l'architecture (I'rincipes d'analyse scientifique) l'aris, 1972, 1. II, pl. VIII, 56, la nomen-

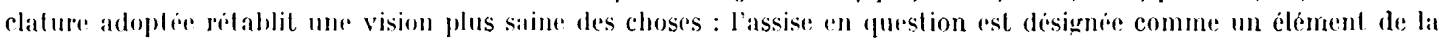
lase de la colonne. Il y a lit autre chose et plus qu'une querelle de mots : il y va de la comprehension d'un parti architectural, ct aussi d'un probleme chronologique.

4.4 L'exemple du temple d'Apollon in Circo est à col exard significatif. Cf. P. Gros, Aurea Templa, Recherches sur l'archilecture religieuse de kome à l'epoque d'Augusle, 13ome, 1976, p. 227 et n. 226 . 


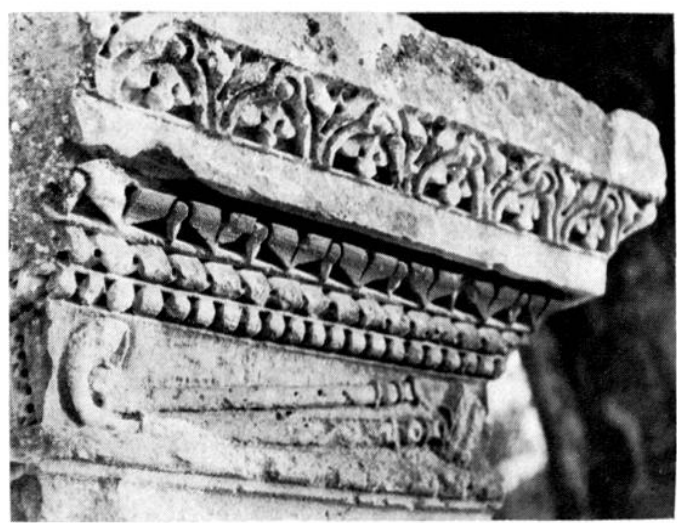

11 Imposte de la face ouest, an nord, de l'are de (ilanum ! pl. 59, 1, de I.'are de Gilanum:

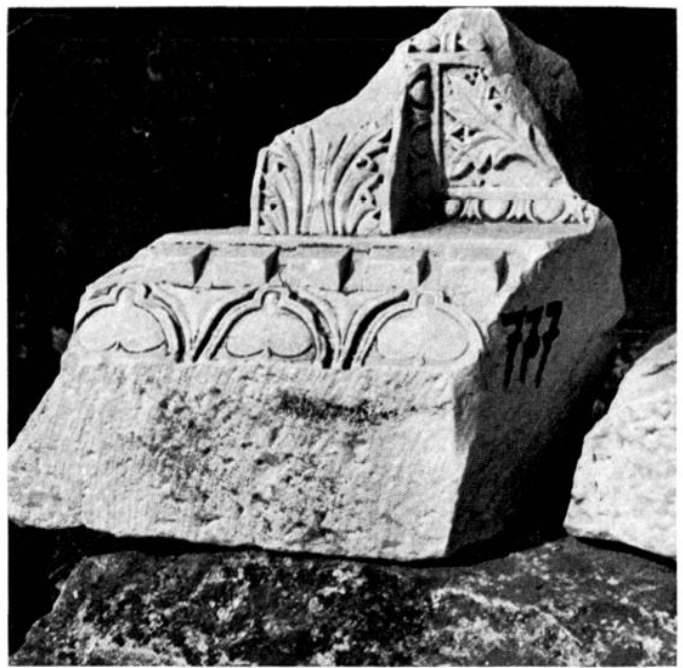

12 Eliment de corniche provenant du theatre ditres idecor de la scaenae frons.

Xarbonnaise, cest l'une des premicres du genre à présenter une moulure concave d'une importance relative aussi grande par rapport aux moulures convexes d'encadrement45; le stade de la Maison Garrée, ou pourtant l'orthodoxie des bases atliques est déja acquise, se trouve ici dépassé, comme il l'est à l'arc d'Orange. Et il suffit là encore de jeter un coup d'oril aux bases beaucoup plus écrasées du mausolée voisin, pour sentir l'écart chronologique se creuser entre les deux constructions6.

Les moulures d'imposte sont remarquables par leur décor comme par leur profil (lig. 11). Sous une sorte de haut abaque, rigne un petit larmier surcreuse en goutte entre deux lalons. Vue en façade, cette imposte offre une réelle harmonie entre les parties verticales lisses et les transilions moulurées. Du haut vers le bas, on passe du talon orné de rais de cocur en "Bügelkymation", au Lalon à rais de cour en "ścherenkymation ${ }^{47}$; on passe de la tresse a la ligne de perles, la seconde moulure constituant a chaque fois une sorte de contrepoint mineur de la premiere. Les rais de corur sont traités avec un souci de compréhension du molif trís supérieur à ce qu'on observe dans divers: monuments provengaux. En particulier, le "Bügelkymation "semble ignoré en Varbonnaise avant l'époque auqustéenne, et il est inutile de rappeler qu'on n'en trouve nulle trace au mausolée ${ }^{48}$.

Parmi les plus anciens exemplaires, signalons ceux qui ornent le talon du couronnement de la frise du pont de Saint-Ghamas, ceux qu'on observe dans les cryptoportiques d'Arles sur un élément de corniche provenant sans doute du forum el, à Arles toujours, ceux d'un fragment de corniche de la scaenae frons du théâtre. Ces spécimens apparliennent lous, de facon signilicalive, a des constructions qui se laissent dater par leurs chapiteaux, rinceaux ou modillons, des années

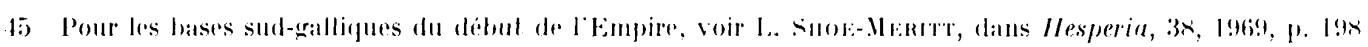

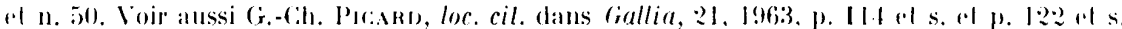

46 (if. Le mansolie pl. 1:-15) ot pl. 19.

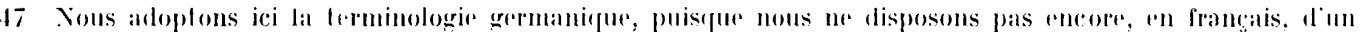

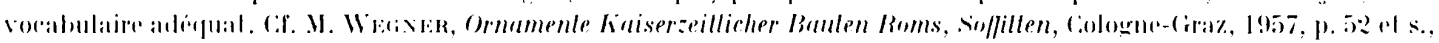

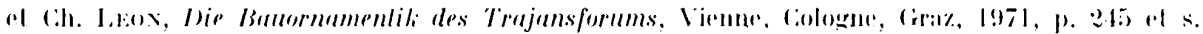

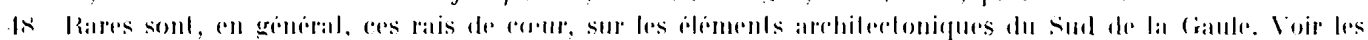

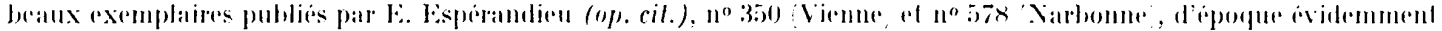
plus lardive. I"n remarequable "Bägelkymation " flavion orme une corniche conservé dans la cour du musce archeolog̣ique doranger. 
$20 \mathrm{av}$.J.-C.49. Or cette moulure. qui vaut d'abord par la finesse de l'exéculion, et se prète en théorie à tous les raffinements, est encore traitée, sur le bloc du théâtre d'Irles, presque à la façon d'un épannelage (fig. 12). Le second jalon important, dans l'évolution des "Bügelkymatia " de la région, est celui de la Jaison Garrée : au couronnement de la frise, les arcs, non jointifs, sont très évasés, et s'apparentent encore davantage, singulier relard lypologique, à ceux de l'arcus Augusli qu'à ceux, trés élancés, du couronnement de l'architrave du temple de Mars Lltorón. A l'arc de Cilanum, la délicatesse et la complexité du motif, ou la "tulipe" apparait pourve d'un pistil central, au contraire de ce qu'on observe au temple de Nîmes, et où la "fleur pendante " est habilement découpée en lobes, allestent que, dans le contexte régional, un nouveau pas a éti franchi. On retrouve à peu près exactement le mème schéma et le mème rendu au couronnement de l'archivolte du grand arc d'Orange.

Si l'on en vient aux extraordinaires guirlandes de fruits et de feuillages de l'archivolte, on aborde un motif-clé, véritable manifeste qui, tant du point de vue décoratif que du point de vue symbolique, revêtait sans conteste une importance de premier ordre aux yeux des constructeurs (fig. 13). Ces guirlandes de Glanum, magnifiquement conservées, sont très semblables à celles des archivoltes nord et sud dlu grand arc d'Orange, où elles apparaissent malheureusement plus dégradées ${ }^{51}$. On observe dans l'un et l'autre cas la même répartition dés fruits en groupes homogènes, séparés par de discrets lemnisques qui, loin d'assurer la cohésion et l'enroulement des divers éléments, servent seulement à isoler chaque catégorio de la suivante. Les mèmes particularités dans le traitement de certaines plantes, comme par exemple les aiguilles et pommes de pin, rendent encore plus patente la parenté entre les deux ares ${ }^{52}$.

Ce curieux cloisonnement, dont on peut suivre le détail à Glanum, se répartit en séries symétriques sur chaque demi-archivolte, et disparaît seulement sur la clé, où les guirlandes venues de droite et de gauche se confondent dans le feuillage de l'olivier. Il évoque peut-être le rythme des saisons, ces commutationes quadripertitas ad maluritatem frugum dont parle Cicéron ${ }^{53}$, dans la mesure où se retrouvent, de la figue alu raisin et à l'olivier, les fruits qui mûrissent successivement du début de l'été à la fin de l'automne, le pin symbolisant sans doute, comme il le fera beaucoup plus tard sur les diptyques consulaires ou le monnayage des decennalia, la saison hivernale ${ }^{54}$. L'intention symbolique, admirablement servie par des sculplores aussi attentifs à la vérité naturaliste qu'au rythme et à la répartition harmonieuse des volumes, était en tout cas de suggérer l'uberlas, cette prospérité sans cesse renouvelée de la nature, liée à l'idéologie millénariste de l'âge d'or ${ }^{50}$.

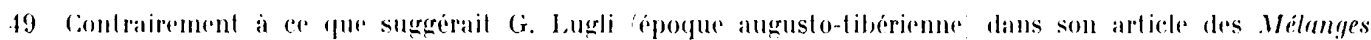

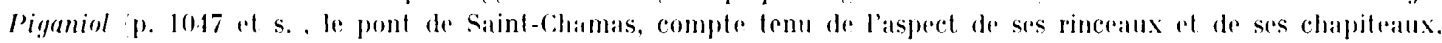

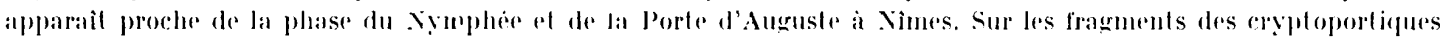

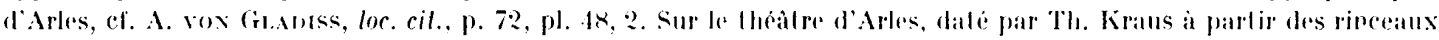

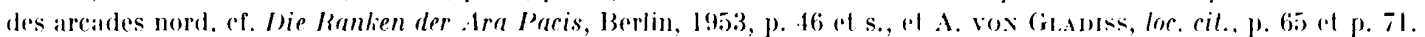

jo) Ces rais de corme ornent, a la Jason Carreg, le lalon de fransition entre frise el denticules. Sur leur analyse slylistique, ef. R. Amr, P. (ikos, op. cil., a paraitre.

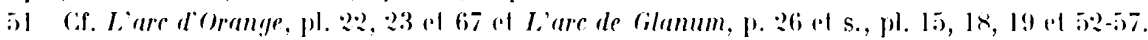

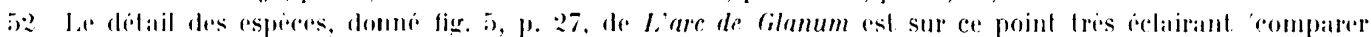

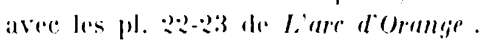

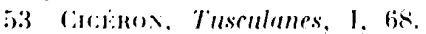

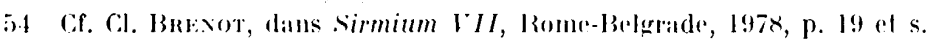

5j Voir sur ce point l'analyse de l'iconographie de l'aurea aelas par E. Sinox, dans Ara l'acis dugustae (.M.1.1 l). Tübingen, 1967, p. 13 if s. 


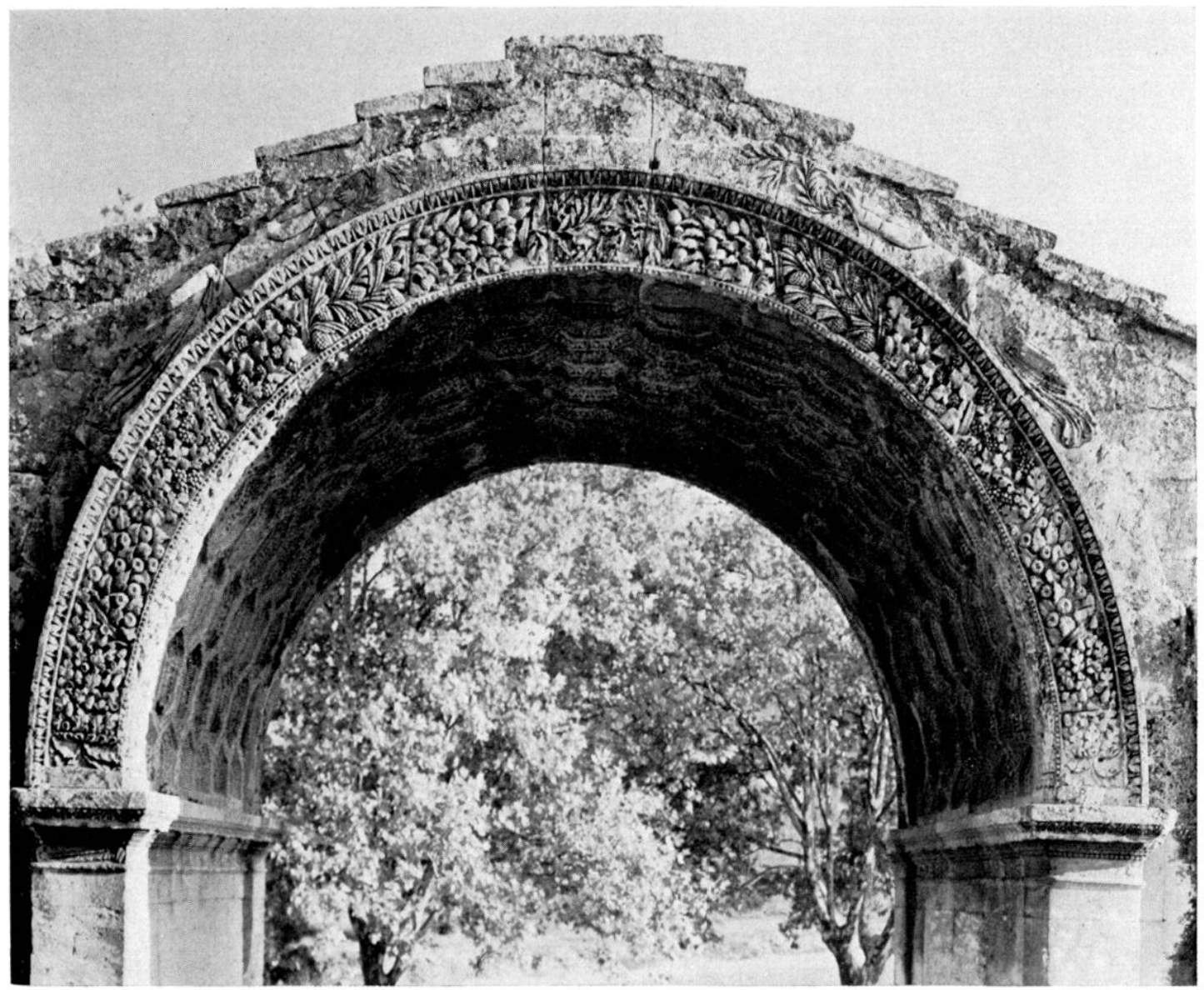

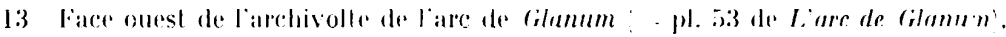

L'esprit et l'apparence de ces compositions sont lrès différents de ceux des guirlandes romaines et italiennes étudiées par M. Honroth, ou le mélange systématique des différentes espéces est une rògle essentielle ${ }^{56}$. Plusieurs décors de la seconde moitié du $\mathrm{I}^{\mathrm{er}}$ s. av. J.-G. présentent cependant des similitudes thématiques avec celui de Cilanum : ce sont, principalement, la guirlande peinte i l'intrados de l'un des ares de l'oecus tricliniaris de la casa del criptoporliro à Pompéi ${ }^{57}$, et celle, en bas-relief de marbre, qui orne le tombeau circulaire de Casal Rotondo, sur la via Appia ${ }^{58}$. W. von sydow, qui vient de publier ce dernier monument, a recensé les variantes ilaliques du molif, sans peut-être toutefois distinguer assez rigoureusement les schémas où se mèlent toutes les plantes, de ceux où elles sont reclassées par espices. C'est ainsi qu'on ne saurail faire entrer dans la mème série les guirlandes de la frise du temple rond de Tiroli el celles de Gasal Rotondo ${ }^{59}$.

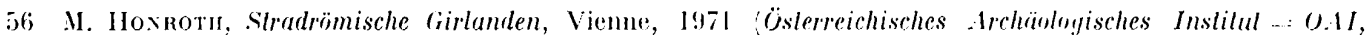
Sonderschrift XVIj.

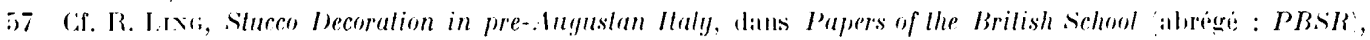

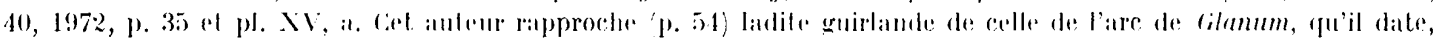
d'apres II. laolland, du trosisime quatrt du $1^{\text {er }}$ s. als. J.-C.

5x Cf. W. vox sisow, Eine Grabrohunde an der Vin Appia Anlicu, dans Jahrburh des denlschen archäologischen Instiluls abregi: :J/.1I, 92, 1977, figr. 13, 14, p. 258-259 et fig. 29 p. 275.

59 Ibid., 1. 27.1 al s. 


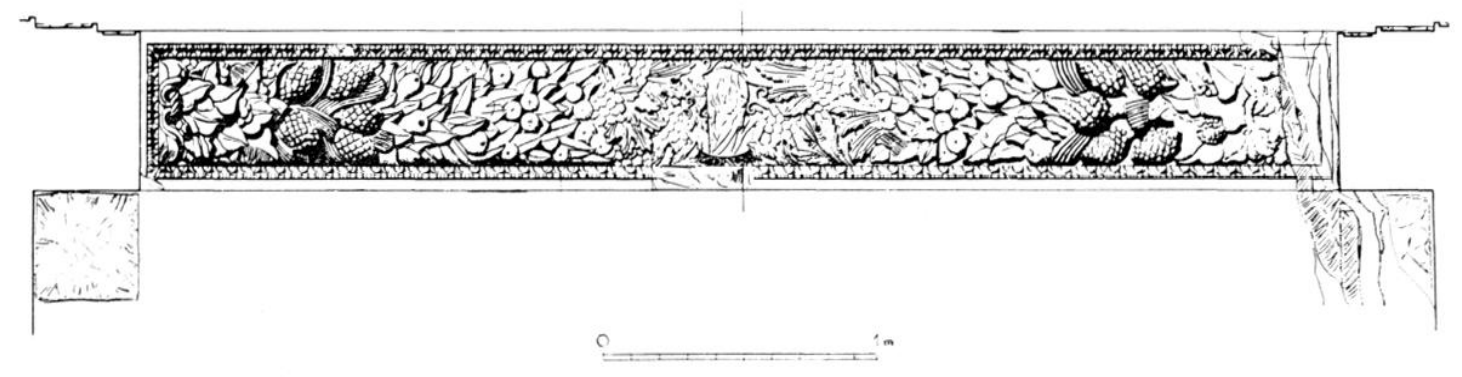

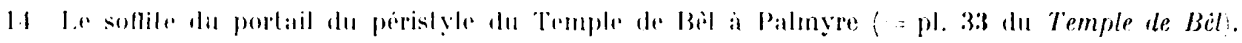

Mais, mème si l'on s'en tient à ces dernieres, il ext difficile d'y voir autre chose que l'une des premières apparitions, encore bien timides, d'un motif, qui semble en revanche avoir trouvé un plein épanouissement sur les deux arcs de Narbonnaise. L'espare disponible plus large el plus continu des archivoltes ne suffit pas à expliquer la netteté du relief, le réalisme du détail, et l'impression d'ensemble, faite de luxuriance el de vigueur, qui ravissent le spectaleur à Glanum. La sécheresse linéaire, encore lrés "néo-classique», des reliefs de la vie Appia, ne préfigure nullement une telle ornementation, qui trouve au contraire un écho inaltendu sur le soffite du portail du péristyle du temple de Bîl a Palmyre ${ }^{60}$ (fig. 14;. On a la, comme l’indique E. Will, un décor exactement similaire, dans le choix, la répartition et le traitement de ses composantes, ainsi que dans la façon dont il occupe le (hamp ${ }^{61}$. I a seule différence, qui naffecte en rien l'aspect général, tient au fait que la guirlande syrienne nollre pas de lemnisques.

En toule hypothese, l'evolution du motif, dont l'origine hellénistico-orientale n'est guire douleuse, paraîl, a Cilanum comme a Palmyre, parrenue au mème starde. si l'on songe que les ornamenla du lemple de Bèl, dédicacé en 3:2 ap. .J.-C., ont dù çre réalisés à la fin du régne d'Auguste et sous celui de Tibere ${ }^{62}$, on relrouve la une forte présomption en faveur d'une datation tardive de l'are de Gilanum.

Sur les douelles d’intralos, apparait un schéma ornemental assez complexe, inspiré sans aucun doute des pilastres de l'Ara Pacis, mais traite avec une liberté et un génie inventif qui, sans tralie lesprit du motif générateur, so plaisent au developpement de plusieurs themes restés jusfu'alors implicites ${ }^{63}$. Il s'agit, pour la douelle orientale, d'une variation sur le rinceau d'acanthes, déployé symétriquement le long d'une lige-candélabre; le mouvement de l'arabesque, sans aucune raideur mécanique, malgré sa régularité, s'enrichit d'harmoniques assez belles, tel le theme fugitif de la lyre, qui se déploie quand l'enroulement se fait vers l'intérieur, et que les volutes s'affrontent directement au contact de la tige centrale (fig. 15). A la douelle occillentale, le motif du candélabre l'emporte sur celui des rinceaux, et des culots successifs reprennent, sur le mode végetal, comme le note H. Rolland, l'image des plaques horizontales ciselées qui animent les grands candélabres métalliques re tradition hellénistique. Ies piliers du tétrapyle de Cavaillon, beaucoup

60) 11. Awr, Le temple de Bil it Palmyre, .16um, Paris, 1966, pl. 33.

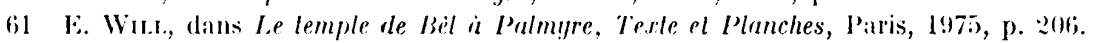

62 Cif. E. Witr, ibial., p. 119 in s.

6.3 Cif. L'are de Glanum, p. 2x et pl. 20. 

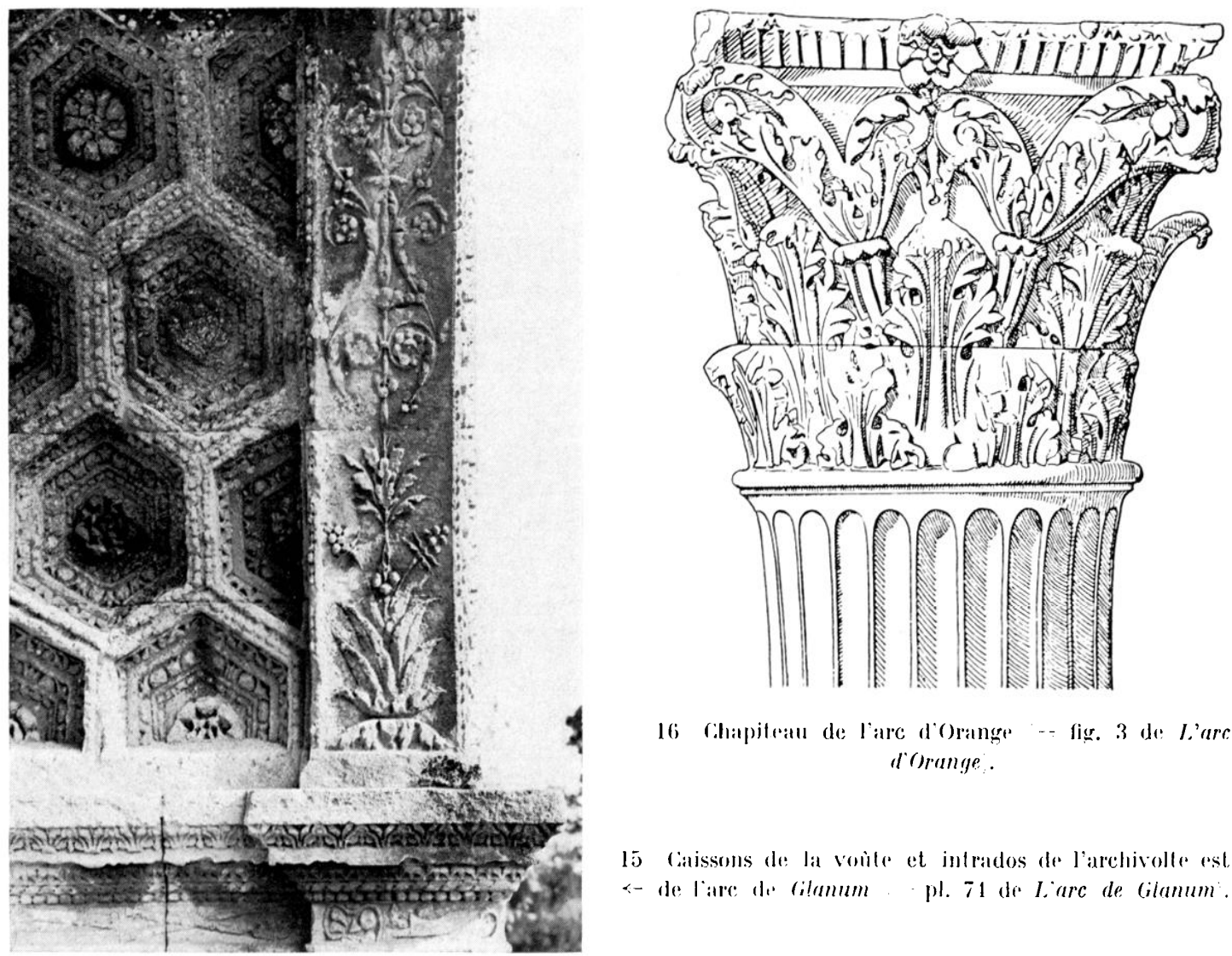

16 rhapiteall de l'arc dorange - fig. 3 de lo'are dorange.

15 Caissons de la voute et intrados dre l'archivolle est 4- de liare de Gilanum pl. 71 de Liarc de cilanum.

plus proches du modèle romain, reproduisent avec plus de fidélité les grands rinceaux du registre inférieur de l'Ara Pacis ${ }^{64}$. Il semble que nous ayons affaire, à Glanum, à une phase plus avancée de la réflexion sur les cartons issus de cet édifice.

Enfin les caissons de la roùte, dont le profil est exactement semblable à ceux de l'arc d'Orange, et qui se distinguent seulement de ces derniers par des détails infimes au niveau du décor, appartiennent à la catégorie la plus élaborée : ces hexagones très surcreusés, à trois paliers successifs séparés par de lourdes moulures, n'ont plus rien de commun avec les caissons tardo-républicains cantonnés par une baguette imitant des lattes de bois, ni même avec les caissons proto-augustéens cernés par un simple talon ${ }^{65}$. Ils supposent acquises les expériences monumentales des temples médio et tardo-augustéens, et reprennent, en les surchargeant, les schémas d'animation les plus riches des surfaces de: converture ${ }^{66}$ (fig. 15).

6.4 Voir infra, p. 76.

65) Pour l'ovolution des caissons à la fin de la Répubiqque ol an début de l'Empire, cf. J. B. Ward Perkixs,

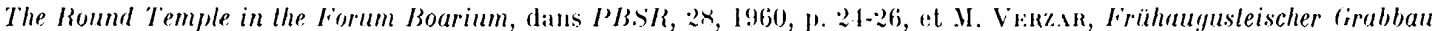
in Sestino (Toscana), dans . WEFR.1, $\times 6,1974$, p. 400)-104. Des tombeaux d'Isernia, de Capoue el de Pompéi tombeau à guirlandes', le temple des IDioscures à Cori en la tample rond de Tivoli offrent d'excellents exemples du schéma le plus simple 'bande plate saus moulures. L'apparition diun encadrement à double décrochement est caractéristiquur

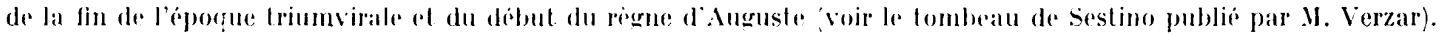

66 Le crousment du champ of la complicalion des modénatures dencadrement, directement imites des 
La convergence de ces diverses observations, les références "romaines " qu'elles suggèrent, mais aussi les situations relatives quelles imposent a l'intérieur des séries provençales, nous orientent pour cet are de Glanum vers la dernière partie du règne d'Auguste et le début du règne de Tibère, disons la seconde décennie du I ${ }^{\mathrm{er}}$ s. ap. J.-C:

L'are d'Orange, si proche à tant d'égards, doit ètre son contemporain ou tout an plus son cardet de quelques années.

La modénature y apparait en eflet, nous l'avons dit, tout à fait analogue dans ses grandes lignes, arec parfois un pas supplémentaire dans l'évolution des motifs, ou une annexion nouvelle dans le répertoire décoratif. C'est ainsi qu'on retroure, à la base du socle des colonnes, le tore déjà présent à Glanum (fig. 8, mais cette fois le profil se complete d'une doucine et d'une double baiguette terminale, reproduisant ainsi celui de la base du podium du temple des Dioscures du Forum, dans sa version tibérienne ${ }^{67}$. Bien qu'elle n'ait jamais été notée, cette dérivation est évidente; la mème modénature réapparaît, à Orange, au socle du second attique (fig. 19).

En pleine concordance avec cet indice chronologique, les chapiteaux de l'ordre engagé ont été remarquablement analysés par $\mathrm{W}$. D. Heilmeyer ${ }^{68}$. Soulignant qu'ils procédaient apparemment des mêmes morlèles romains que ceux de la Maison Garrée, cet auteur montre qu'ils s'en éloignent cependant par la présence d'une feuille acanthisée recourrant la frange supérieure des volutes el des hélices (fig. 16); ce "Fiederblatt 》, caractéristique du corinthien tardo-augustéen, et présent au temple des Dioscures précisément ${ }^{69}$, fait entrer les chapiteaux d'Orange dans la série de ceux de Pola, de Vaison et des chapiteaux julio-claudiens du musée de Nìmes ${ }^{70}$.

Quelques détails du décor apportent une confirmation à l'hypothèse d'une date un peu plus tardive que celle de l'are de Gilanum : au couronnement des archivoltes des petits arcs, c'est d'abord le motif schématisé des lleurs de lolus entourant des palmettes ${ }^{71}$ (fig. 17); il s'agit d'un schéma dont on peut suivre l'évolution depuis le ve s. av. J.-G. ${ }^{72}$, et dont $W$. von Sydow a rassemblé très utilement les diverses versions italiques, souvent inédites, de la fin du ${ }^{\text {er }}$ s. av. J.-C. ${ }^{73}$. Ce qu'il convient d'observer à Orange c'est le degré d'abstraction ou, si l'on veul, de dégradation du motif, qui a perdu sa spécificité décorative pour orner une simple moulure de transition : la fleur de lotus délaisse tout aspect végétal pour revètir celui d'un "double dard", selon l'expression de R. Amy, et les palmettes, loin d'alterner avec d'autres motifs, peltes, vases, etc., n'offrent que des variantes minimes, dans le nombre de leurs digitations. Seules les modénatures julio-claudiennes atteignent ce niveau d'évolution à Rome, le meilleur exemple étant fourni par le cavel d'une cor-

edifices tardo-classirues de Grice Tholos d'Epidaure, Frechthéion), sont une innovalion de l'architecture médioaugustéenne, d'abord appliquée aux caissons reclangulaires des portiques des lemples fex. femple de Vlars litor a Rome, . Lusage de caissons hexagonanx ou rhombojdaux peul avoir éte facilite par les expériences réatisées assez tót en Italio sur les voùtes en opus caemenlicium ísanctuaire de Palestrina). Mais la lechni(que du coffrago sur caissons de bois n'etait ividemment d'aucune utilité pour les lailleurs de pierre de cilanum ou d'Orange.

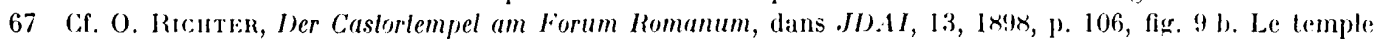
des Dioscures, restauré par Tibiere sur l'ordre d'Auguste, fut consacré en 6 ap. J.-C.

68 W. D. Hentanerer, op. cil., p. 113 et s. Voir la remarquable descriphion de R. Ams, dans L'arc d'Orange, 1). 21 et s. et fig. 3 .

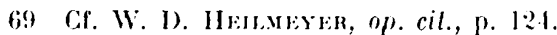

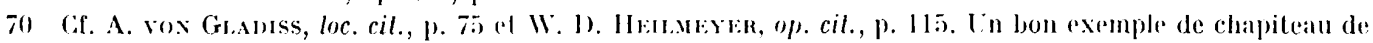

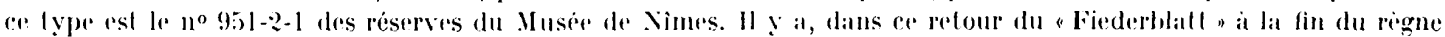
l'Auguste, el pendant une partie de léporque julio-chandienne, une curieuse reminiscence d'une pratique decorative

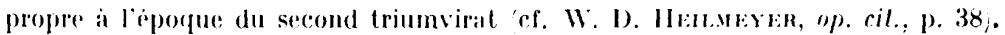

7 C. R. Am, dans L'are d'Orange, p. 2x el fig. 9.

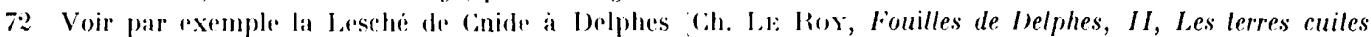
archilecturales, l'aris, 1967 , pl. 1 el pl. 46.

i3 IV. vox sroow, loc. cil., p. 27i) et s., fig. 43-48. 
faces externes

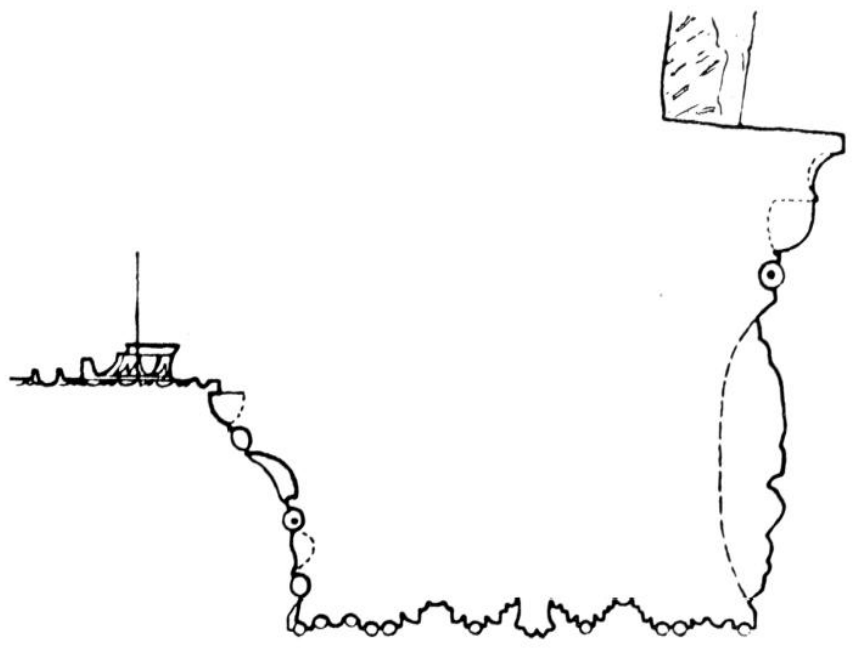

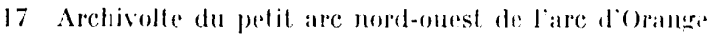

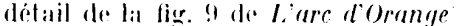
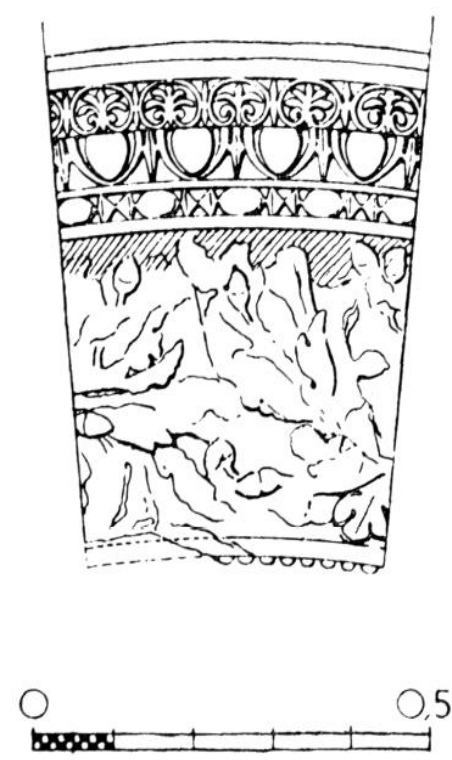

IN Corniche derrierie S. Nicola in Carcere, lome.

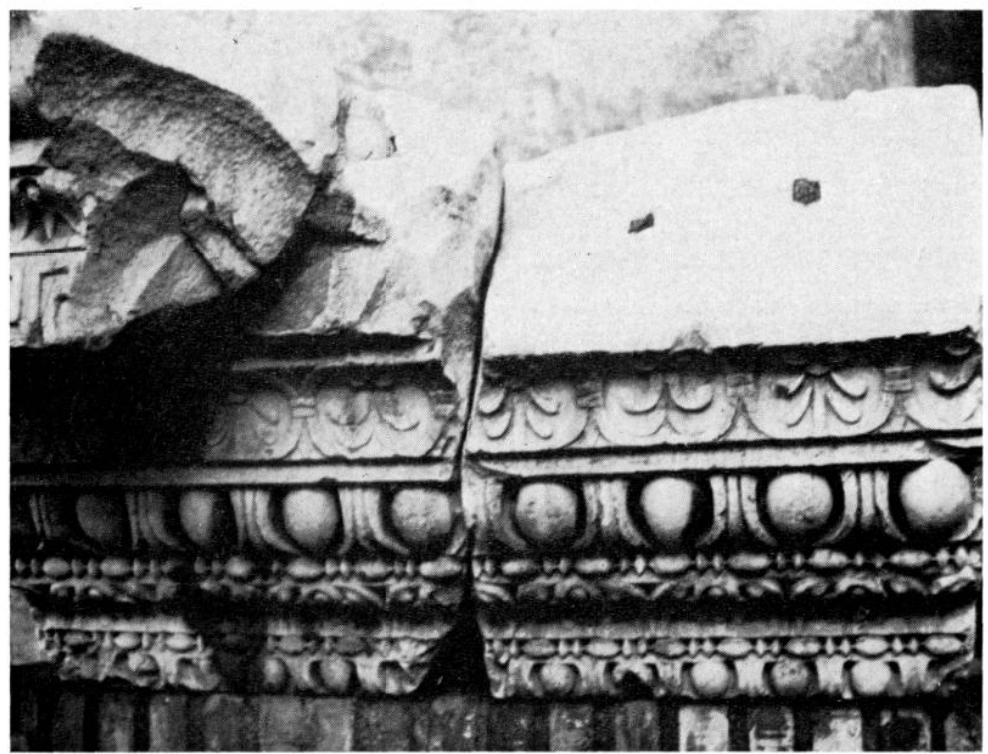

niche de marbre située derrì̀re S. Nicola in Carcere, et datée avec raison par Ch. Leon de l'époque tibérienne $^{74}$ (fig. 18).

On note en outre, au second attique, le décor de la doucine des socles, déjà évoqués : cet anthémion, à fleurs alternativement dressées ou pendantes reliées par des acanthes en sinusoïde, constitue l'une des premières approches julio-claudiennes d'un motif qui aura la faveur des modé- 

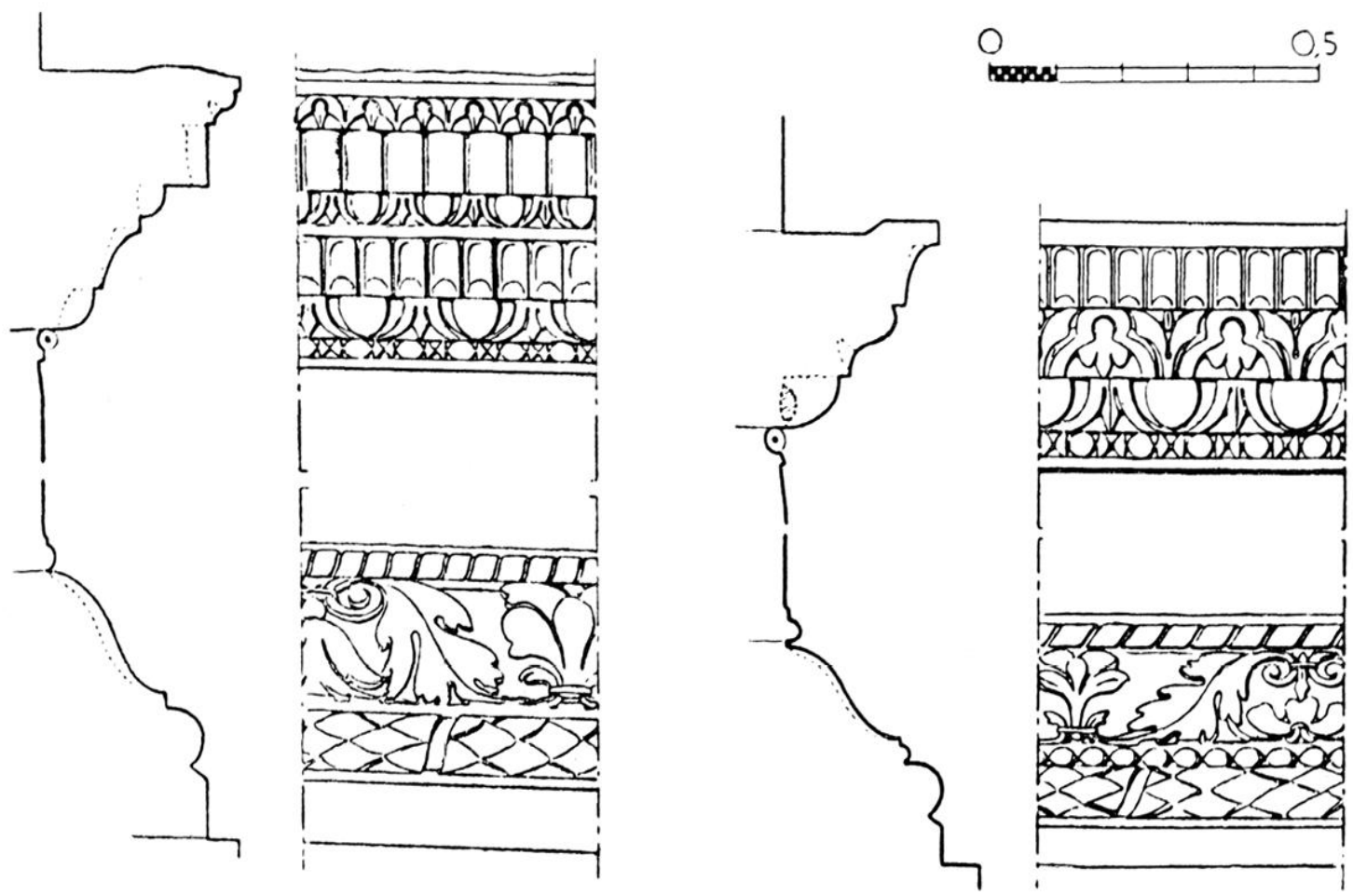

19 Moulures des socles du second attique de l'are d'Orange $=$ = fig. 17 de L'arc d'Orange $)$.

natures flaviennes, ces fameux "Wellenranken", dont Ch. Leon a donné récemment une typologie tries poussée pour les édifices de Rome ${ }^{75}$ (figr. 19).

Sur le même attique, le traitement particulier des oves, déjà remarqué par II. Kähler, avec la petite barre horizonlale qui joint le sommet des "coquilles", ne saurait être négligé : on le retrouvera sur l'arc claudien de Vérone, dit Porta Borsari ${ }^{76}$.

Ces particularités, si infimes qu'elles puissent paraître, n'en constituent pas moins, comme de menus tessons recueillis dans une couche archéologique, des données dont il faut tenir comple. Elles contraignent, croyons-nous, à rapprocher du terme fixé par l'inscription, telle du moins que la restituait $\mathrm{A}$. Pigraniol, l'exéculion des derniers ornamenta ${ }^{77}$. L'analyse stylistique suggérant les années 25 ap. J.-C., on ne saurait retenir l'hypothèse d'un arc construit antérieurement, el "restitué " ensuite a l'kmpereur; il convient sans doute de lire, comme d'ailleurs le souhaitait en dernière hypothèse A. Piganiol lui-mème, restilutori à la seconde ligne de l'inscription, et non pas restituil ${ }^{78}$. Et de fait, le dossier historique de la région montre bien que la période qui convient le mieux a la construction d'un tel édifice a Arausio est celle qui suit la répression de la révolte de Sacrovir en $21^{79}$. De $21-22$ à $26-27$, date de la mise en place de l'inscription, on compte cinq à six années : c'est un laps de temps raisonnable pour concevoir et achever un monument de cette imporlance ${ }^{80}$.

75 (ih. I.sox, op. cit., p. 130 et s.

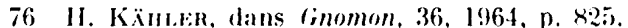

77 A. P'Inavor., dans L'arc a'Orange, p. 143 el s.

78 Ibid., p. 152. Voir aussi H. Käm1.re, dans Gnomon, 36, 1964, p. \$28-9.

79 Tacite, Annales, III, 40-46.

s) Sur les delais de construction des edifices publics au dehut de l'Empire, ef. P. Gros, Aurea Templa, op. cil., p. 65) at s. 
les points étant acquis, on peut tenter de situer, en chronologie relative d'abord, absolue ensuite, les monuments de Cilvaillon et de Carpentras.

La richesse ornementale du tétrapyle de Gavaillon est si remarquable qu'on s'étonne qu'un tel édifice n'ait pas davantage retenu l'attention des archóologues; non seulement aucune monographie ne lui a encore été consacrée, mais il parait mème ignoré des synthèses architecturales les mieux informées ${ }^{81}$. Seule une brève mention dans le livre de Th. Kraus sur les rinceaux de l'Ara Pacis rompt un silence par ailleurs presque total ${ }^{82}$. Ce sont en effet les rinceaux des pilistres qui sollicitent d'abord l'oil de l'observateur (fig. 20 et 21 . L Vee plusieurs fragments de piédroits retirés des remparts d'Arles, el attribués parfois à un "are municipal " ${ }^{83}$, ces reliefs rappellent, de la facon la plus saisissante le décor du registre inférieur de l'Aulel de la Paix Auguste de Rome. Plus encore que sur la frise de la Yaison Carrée, la légèreté des tigres el de leurs enroulements, leurs délicates efllorescences, évoquent presque le savoir-faire d'un atelier urbain. Le mouvement, plein d'équilibre et d'aisance, y est dépourvu de ces lourdeurs qui, à la Mlaison Carrée, proviennent d'erreurs de cadrage et conduisent parfois à écraser la courbure des tiges maitresses ${ }^{84}$. Dans le détail, on relìve, comme directement calqués sur le modele romain, les demi-palmettes terminales el les «bouquets de feuilles ${ }^{85}$. Ces derniers, encore bien visibles, sur la fare nord du pilastre nord-ouest, et sur lit face sud du pilastre sud-est, soutiennent arantageusement la comparaison, malgré un relief moins accentué, qui les maintient dans une étroite dépendance par rapport au fond.

La seule différence notoire avec le schéma élaboré à Rome, c'est que les liges parallíles de l'enroulement principal et de ses pédoncules, au lieu d'ètre dissimulées sur la plus grande partie de leur cours dans la gaine des caulicoles et des calices, restent visibles, et sont reliées les unes aux autres par de capricieux liserons, substituts des bandelettes des rinceaux peuplés du théatre d'Arles ${ }^{86}$. Dès le départ du culot, le caulicole fait défaut, laissant les tiges sortir libres de derriire les feuilles d'acanthes ${ }^{87}$.

Mais l'impression d'ensemble reste très comparable à celle qui se dégage de l'Ara P'acis, et il faut supposer, a l'origine de ces rinceaux de Gavaillon, un carton orlhodoxe, at sams doute encore proche, chronologiquement, de celui de l'archétype.

L'autre élément majeur du décor est constilué par les chapileaux, particulierement préservés sur la face orientale (fig. 22$)$. Avec leurs lobes creusés en coquilles, leurs digitalions en forme de gouttes, leurs caulicoles cannelés faiblement divergents, leurs collerettes en bourrelet, ils s'apparentent au type de la Maison Carrée ${ }^{88}$. Les seuls éléments d'évolution par rapport à ceux-ci se décèlent dans l'accentuation de la rigidité des nervures axiales des feuilles, et dans la préencence, lit encore, d'acanthes enveloppant les volutes.

Si ee dernier trait nous oriente vers une période voisine de celle de l'are d'Orange ${ }^{89}$, on ne saurait cependant attribuer au tétrapyle de Calvaillon une date aussi tardive. Outre

81 W. D. Heilmeger ne recense pas cet edifice daus son chapitre consacere a la Gaule Narbonnaise. On ren

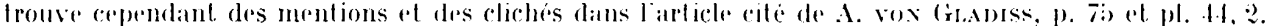

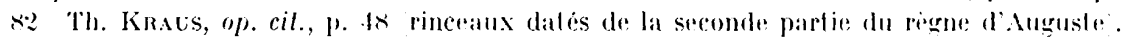

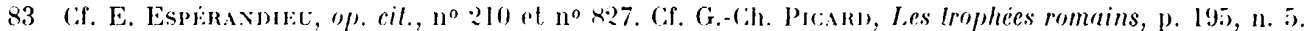

84 Surlout sur la face ouest du temple.

85) On comparera, avec nos figr. 20-21, les pl. 4, 5, 6 de li. sumos, op. cil.

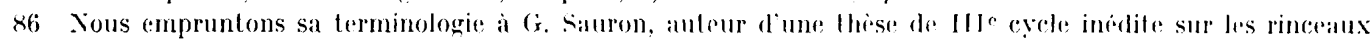
de Narbonnaise.

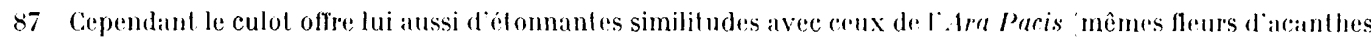
de part det d'autre des tiges maillresse's'.

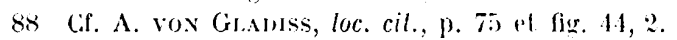

89 (.f. supra, p. 73, n. 68 . 


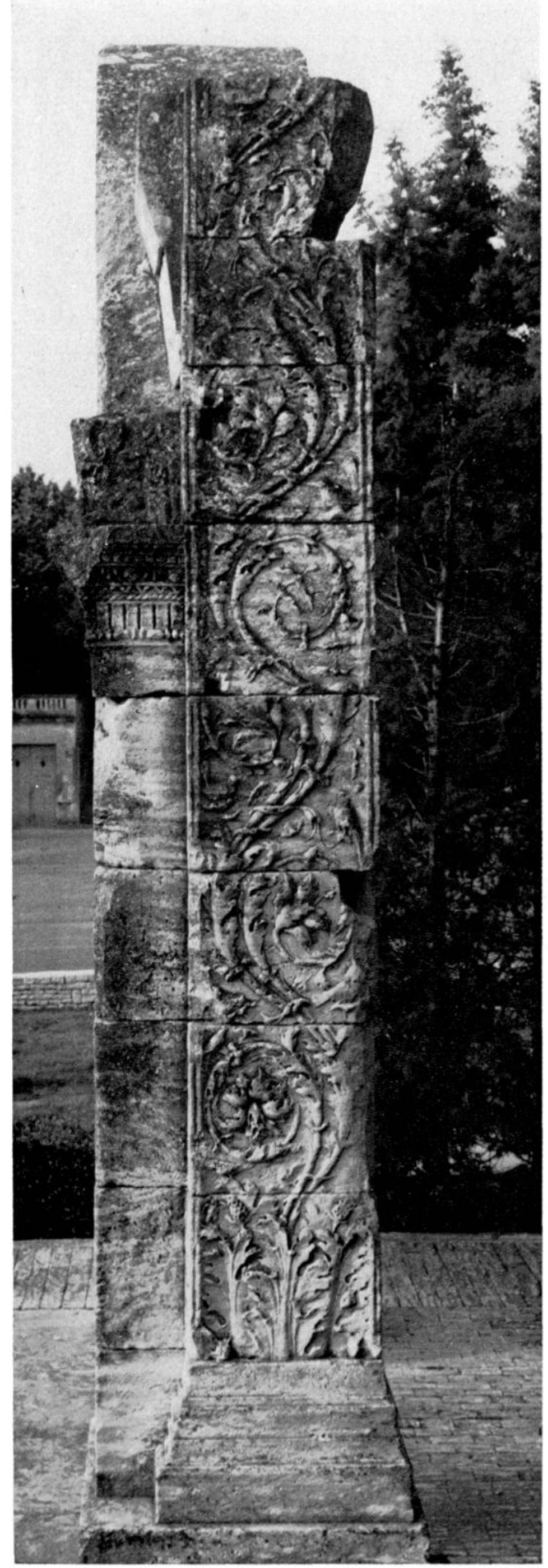

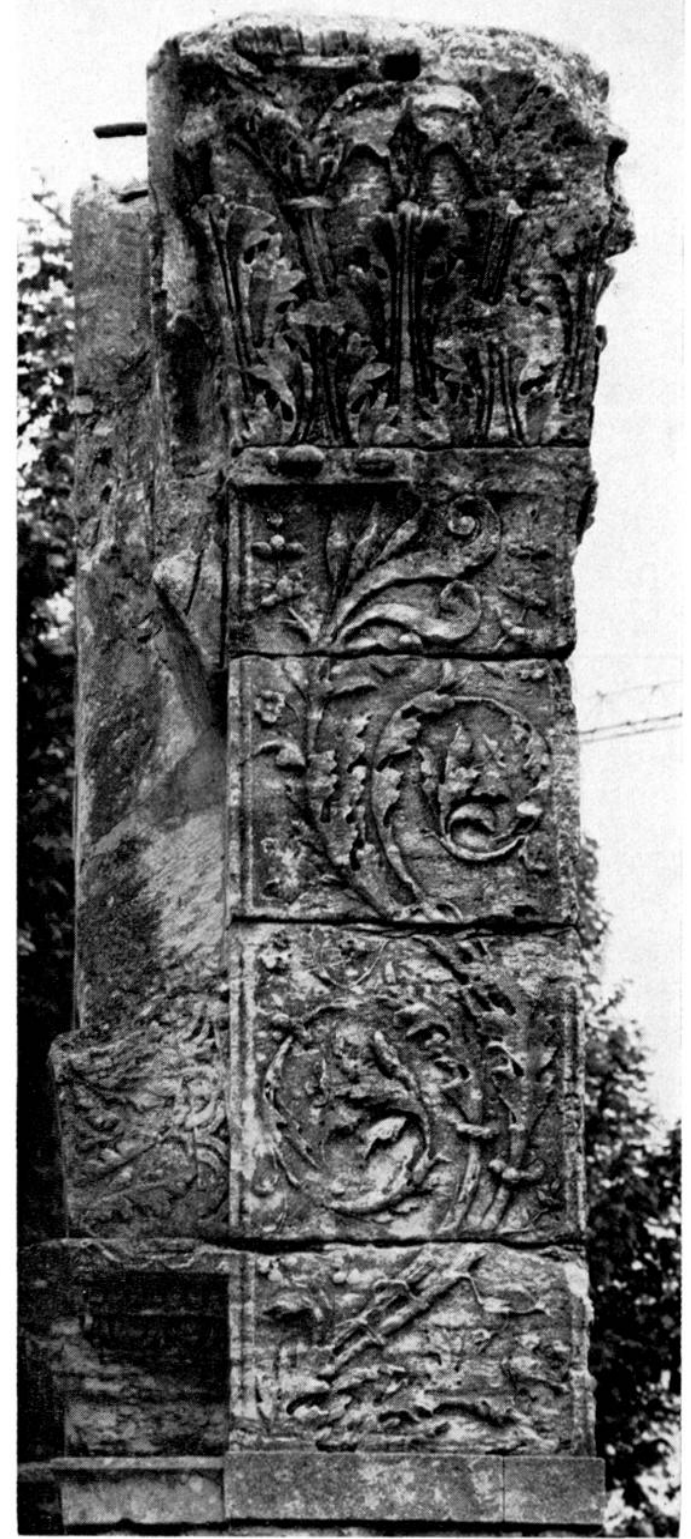

:I liace sud du pilastre sur-est du lemaprle d. Cavaillon

20 faner nord du pilastre nord-ouest du tetrapyle de Caviallon. 


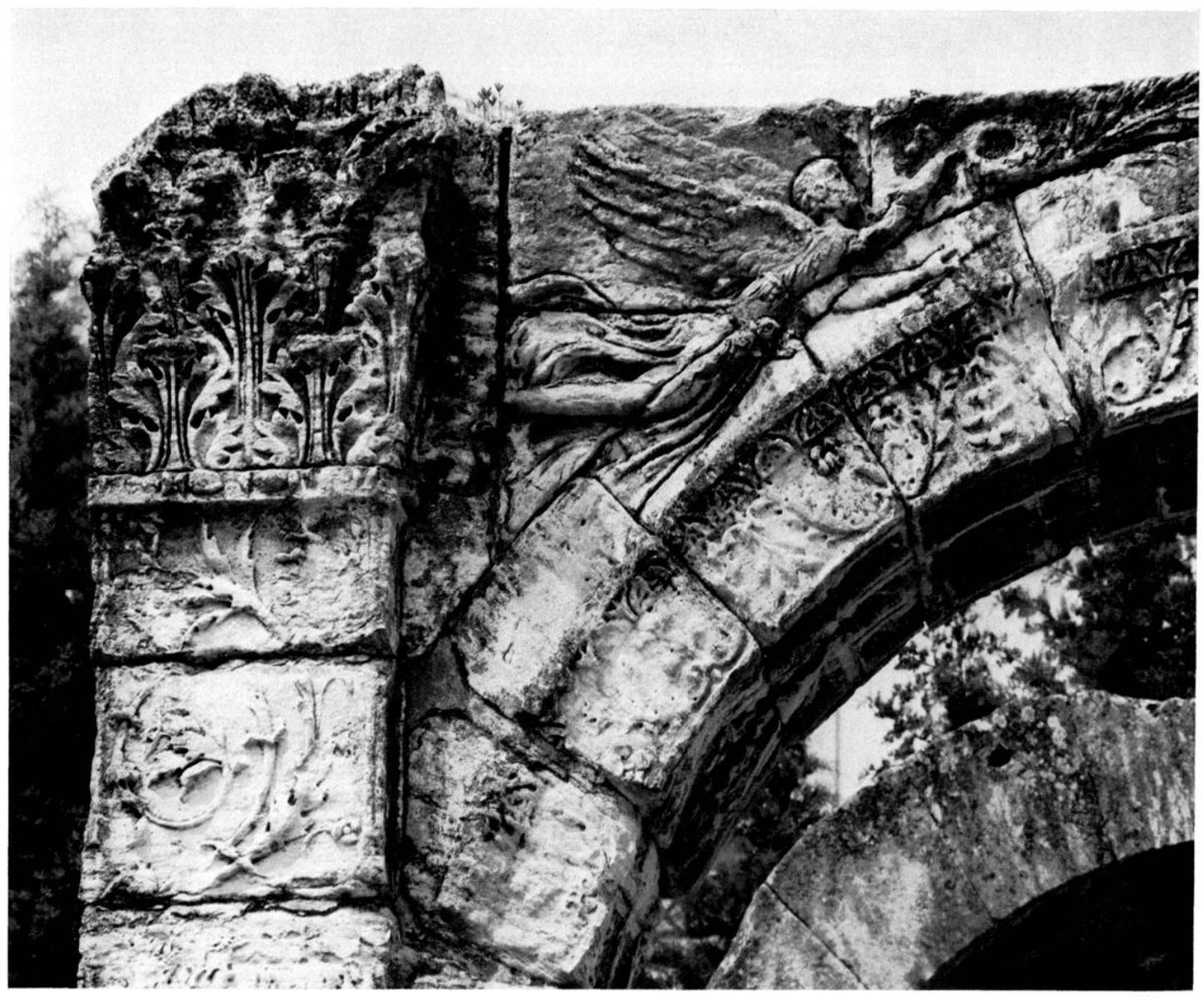

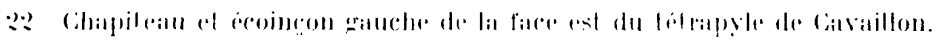

les rinceaux, qui nous interdisent de trop nous éloigner des années du changement d'ère, on doit prendre en compte le motif de l'archivolte : très éligant lui aussi, il offre un type d'anthémion certainement antérieur à celui qui orne la doucine du socle du second attique de l'are d'Orange, car les acanthes qui doivent constituer lo sinusoïle gardent une raideur qui nuit à la cohérence du dessin. L'aspect paratactique de ses composantes est d'ailleurs souligné par l'absence de lien visible entre les feuilles obliques et les fleurs alternativement levées et pendantes. De surcroît, pour remplir le champ, on a dù recourir à l'expédient des petites rosettes qui encarlrent, sans leur être rattachée, les fleurs dressées. Cie sont là les signes d'une phase de gestation, où ne sont fixés ni les rythmes ni les volumes; si le motif nous séduit par sa fraîcheur, c'est précisément parce qu'il ne s'est pas encore figé dans un schéma cursif, où les problèmes d'occupation de l'espace et de continuité linéaire seraient résolus. Xul doute qu'il ne s'agisse d'une sorte de prototype, précieux jalon typologique, qui, à notre connaissance. faisait défaut jusqu a présent pour comprendre la genèse des "Wellenranken " ${ }^{90}$.

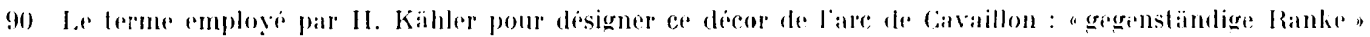

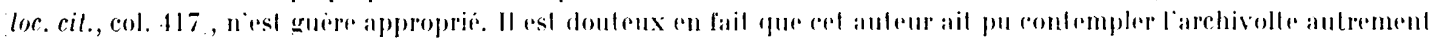
que de loin. 


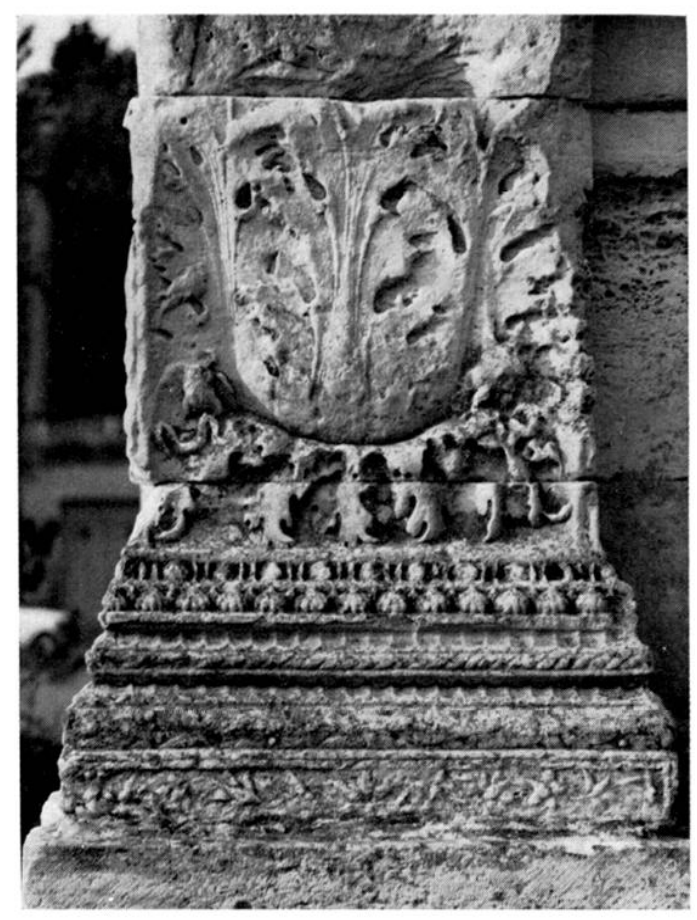

23 Base du pilastre nord-r'st fice nord) du tétrapyle de Cavaillon:

Gelte recherche décorative, qui ne craint pas d'innover, ou du moins d'uliliser des éléments inhabituels, est également sensible a la base et au couronnement des pilastres. Sur la face nord du pilastre nord-est, on peut encore apprécier le profil complexe de la base (fig. 2:3), avec plinthe ornée d'une petite frise végétale, tore couvert d'une sorte de tresse, double scotie à godrons, divisée par une baguelte tressée sur listel, le tout surmonté de deux moulures dont seule la seconde peut être identifié a des perles et pirouelles ${ }^{91}$. Celle qui lui est sous-jacente semble s'apparenter à un "Feigenstab», sorle de rais de cour végétalisé où la feuille en forme de cour (Iterzblatt) serait remplacée par un fruit (figue ou grenade) ${ }^{92}$; l'état de la moulure interdit de préciser davantage, mais on peut songer a tel motil de l'ordre intérieur du temple d'Apollon in Circo ${ }^{93}$. ou d'une corniche "dorique " provenant peut-itre de l'are parthique du Forum ${ }^{94}$. Lin loule hypothese, il y a la un choix inattendu, qui manifeste une grande liberté de la part des sculplores, et contraste étrangement avec l'orthodoxie des rinceaux.

Ia superposition des moulures et des décors des impostes réserve elle aussi des surprises (fiw. 24-25). Si chaque motif, pris isolément, est fort proprement, trailé, la séquence, composée de bas en haut d'un aslragale, de godrons. d'une lresse, d'un "Scherenkymation ", d'oves, de billetles et d'un "sherenkymation" sous abaque, laisse quelque peu perplexe. La face anlérieure de l'abaque présente un petil anthémion stylisé en faible relief qui n'est pas sans évoquer, moins dans son détail que dans son duclus et sa discrétion graphique, l'ornement de la cimaise de l'arc de Rimini ou celui

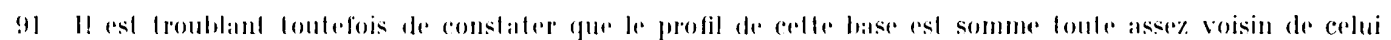

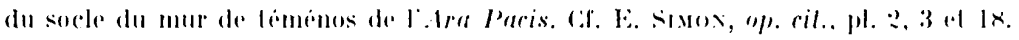

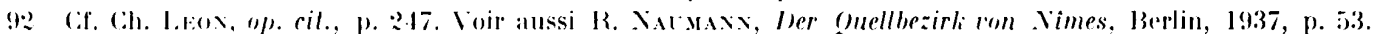

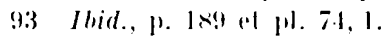

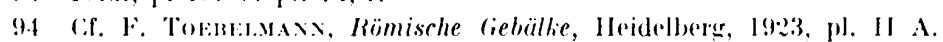




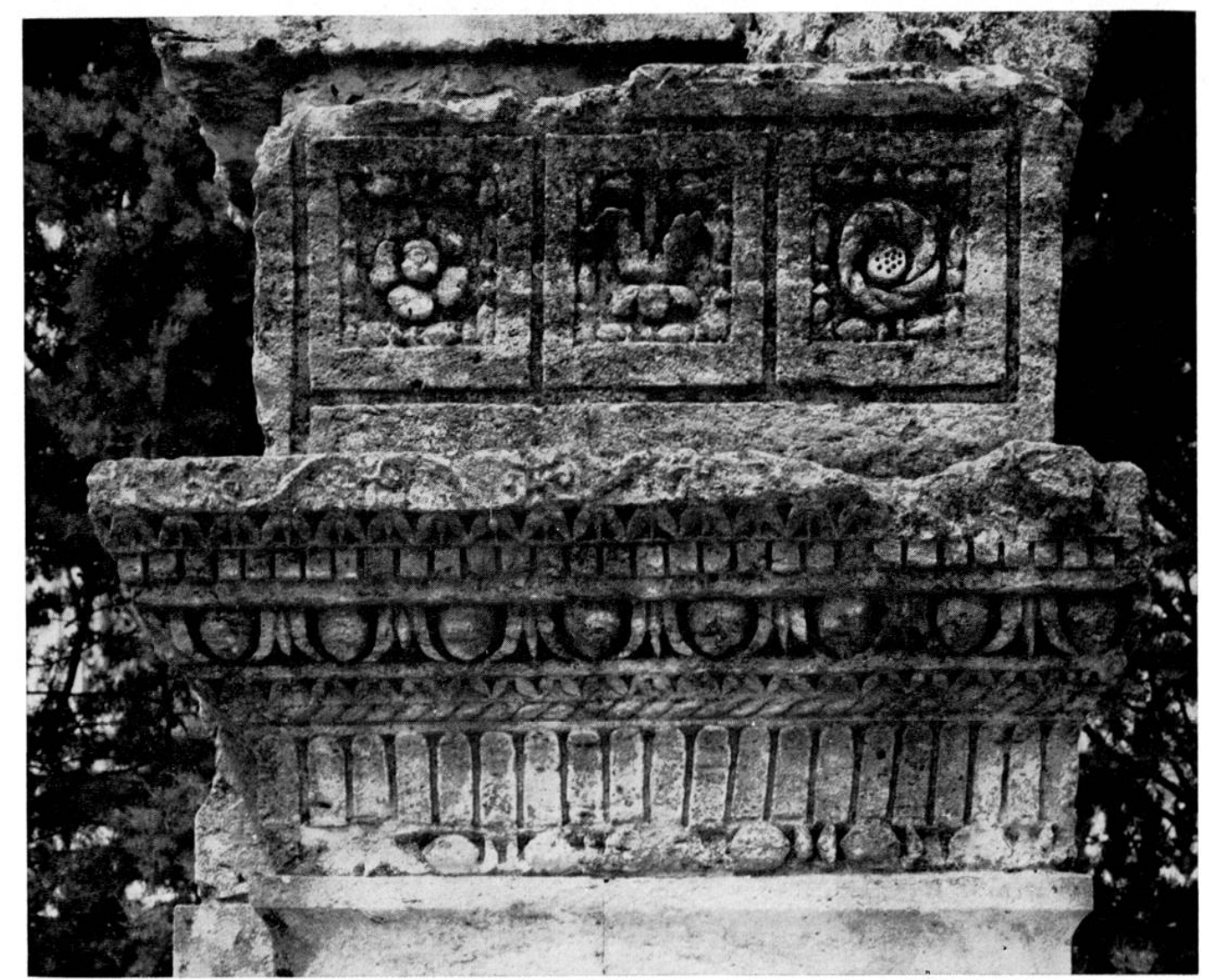

2.1 Pilastre sud-ourst, face est de l'imposte du tétrapyle de Cavaillon.

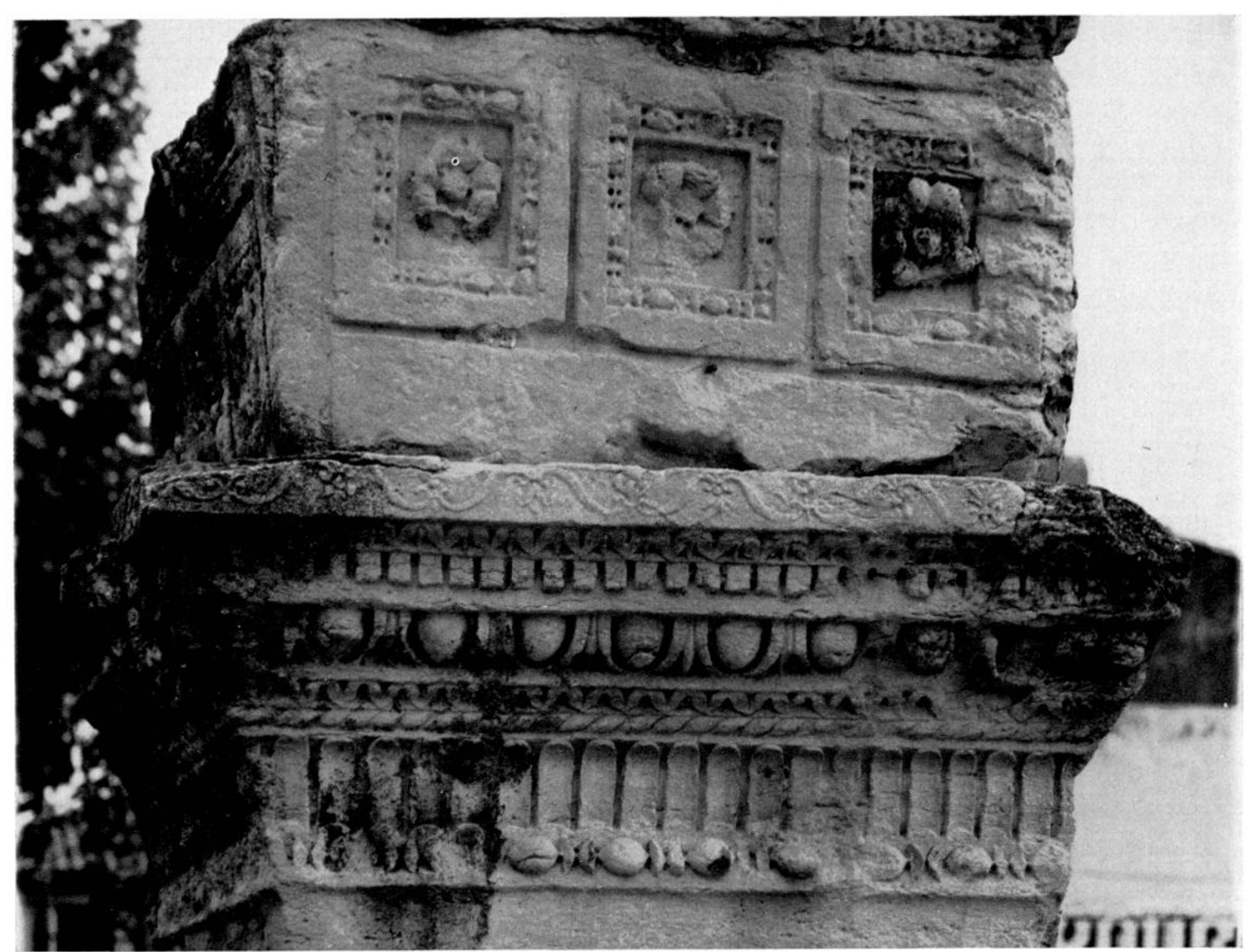

25) Pilastre nord-est, face sud de l'imposte du tetrapyle de Cavaillon. 


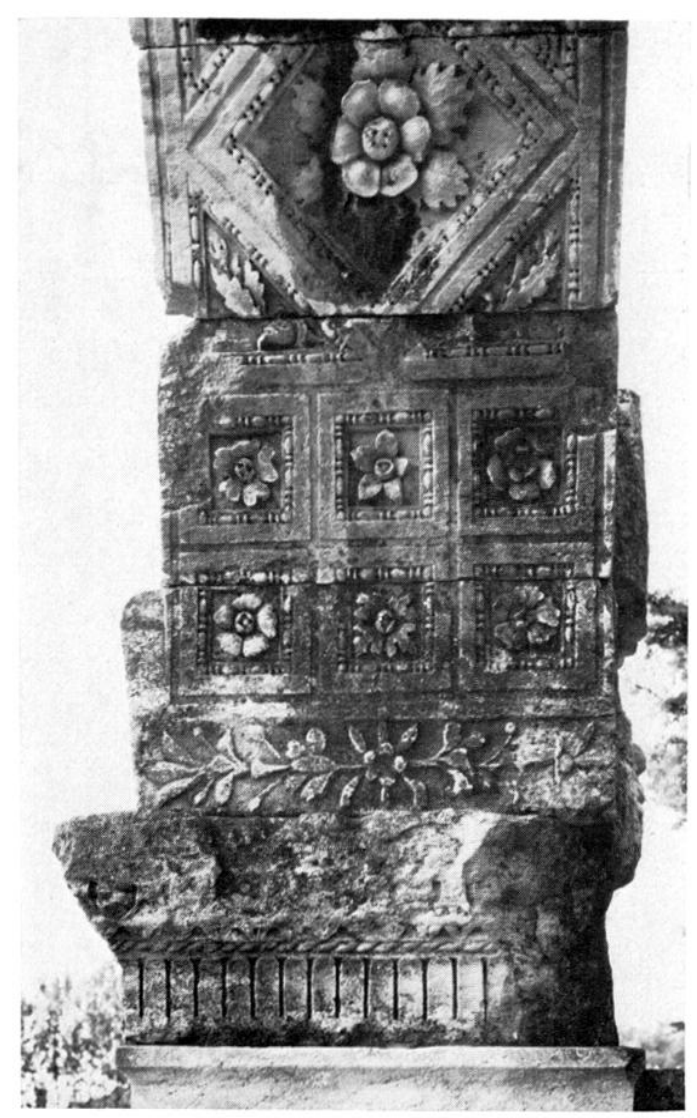

26 Pilastre sud-onest et depart de liareade du tailrapyle de Cavaillon.

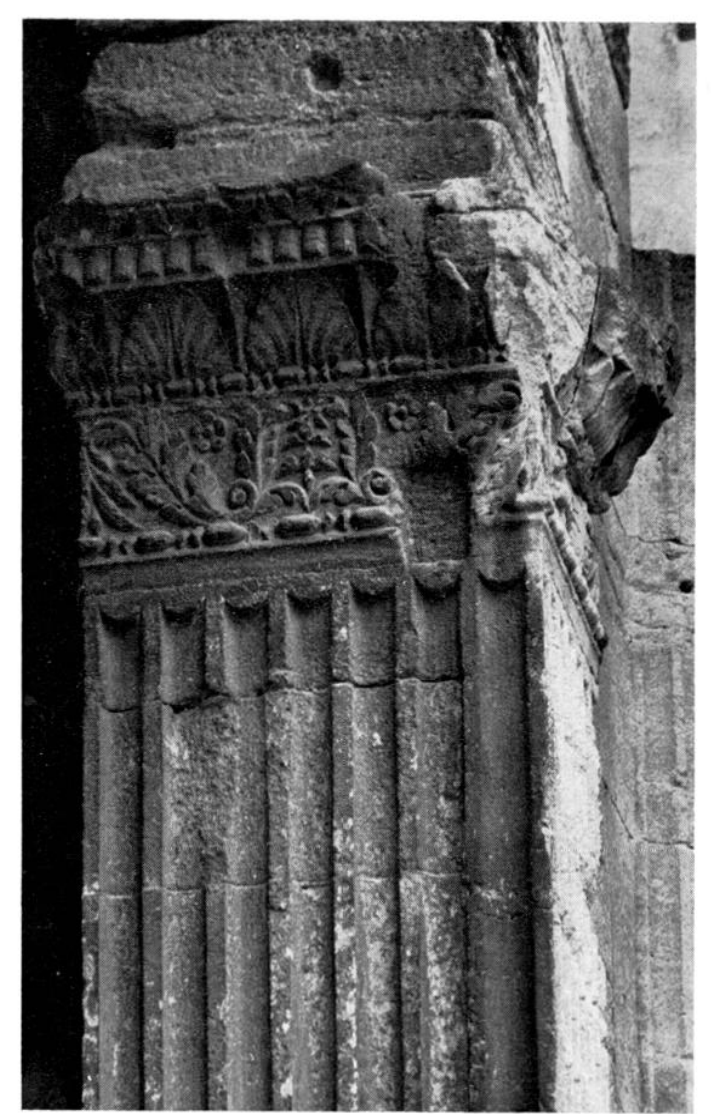

$2 \times$ Detail du pilastre de la fig. 27.

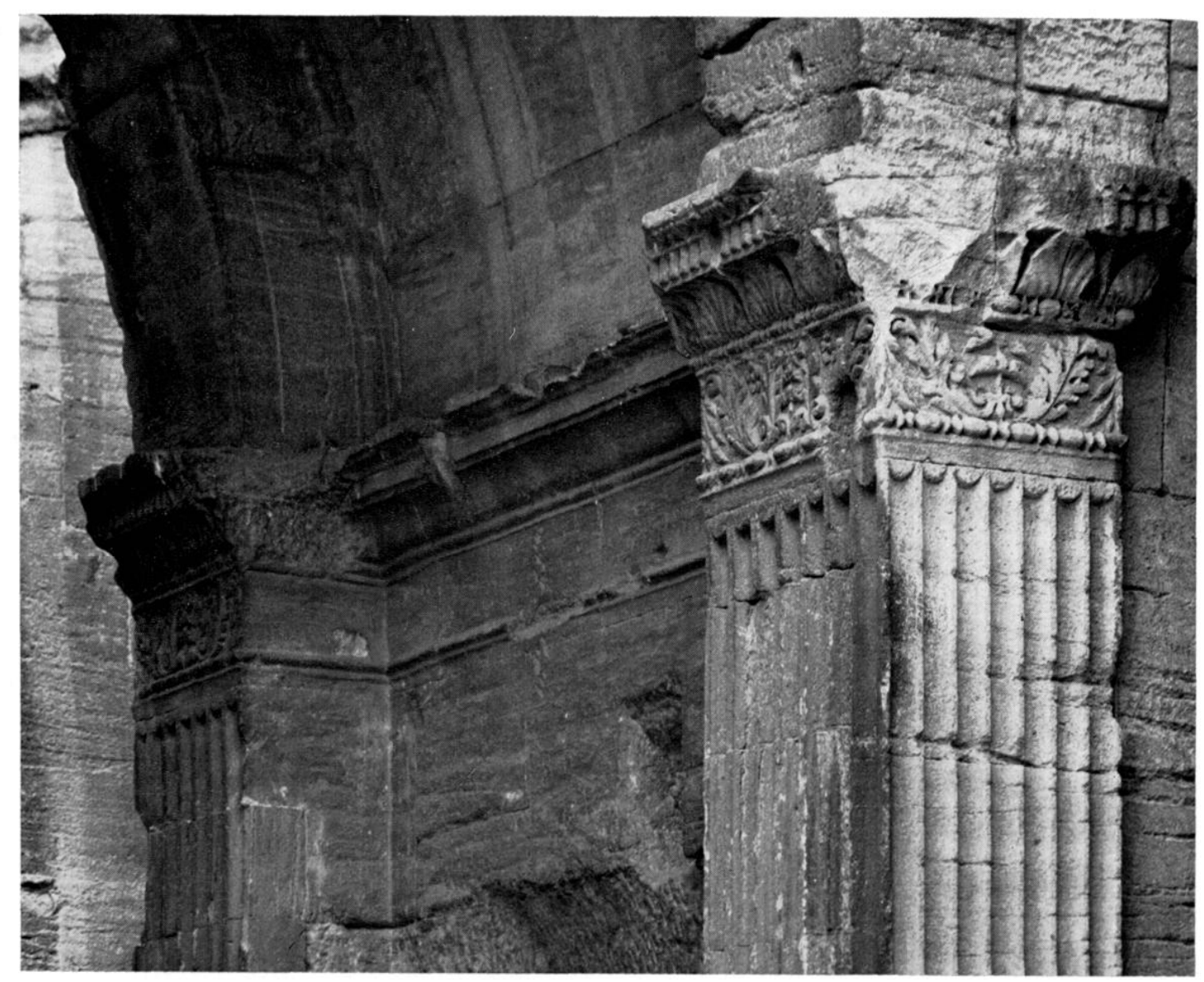

27 Pilastre de droite de la face nord de l'arc de Carpentras. 
de l'ordre inférieur interne de la Basilica Aemilia ${ }^{95}$, rélérences, celle fois encore, étonnamment anciennes par rapport au contexte général.

Quant aux caissons, ils appartiennent à un stade antérieur à ceux de Glanum et dorange (figr. 26). Même si l'on fait la part de la difficulté inhérente à l'étroitesse des arcatures, où le schéma des hexagones pouvait difficilement trouver place, leur faible creusement et la relative simplicité de leur cadre plaident en faveur d'une date plus ancienne.

De ce mélange de données un peu déconcertant il résulte, malgré le caractère tardoaugustéen des chapiteaux, qu'on ne saurait descendre au-delà de la première décennie ap. J.-C. Il semble même que la fantaisie de cet édifice, qui le rend si difficile à classer, tienne en grande partic au fait que ses architectes, pas plus que ses décorateurs, n'ont pu se référer à ces modèles contraignants qu'ont dû constituer, temporairement du moins, pour la région, les arcs de Glanum et d'Orange.

Il en va de même pour l'arc de Carpentras. Si l'on en juge par les éléments, à vrai dire peu nombreux, de son décor architectonique, il paraît contemporain de celui de Ciavaillon : les anthémia qui ornent l'archivolte de sa face sud et le sommet de ses pilastres appartiennent en tout cas à la même série que celui qui règne sur l'archivolte du tétrapyle de Cavaillon (fig. 27-28). I a datation ainsi suggérée s'accorde sans peine avec celle qu'a proposée G.-Ch. Picard à partir de l'examen des captifs représentés sur les facades latérales ${ }^{96}$.

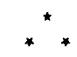

Telles sont les données que nous tirons de l'analyse architecturale et stylistique de ces edifices. Si, pour plus de clarté, nous les replacons dans leur ordre chronologique normal, nous obtenons la séquence suivante :

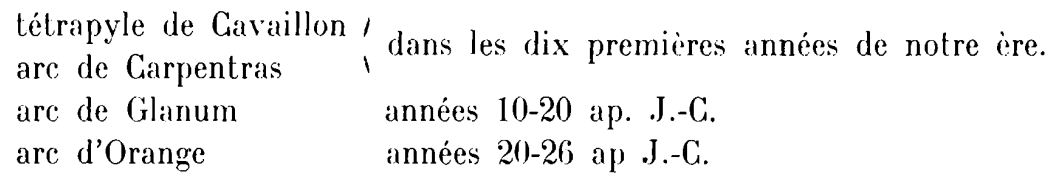

Il n'est pas indifférent de noter que ces monuments, qui paraissent élevés à la gloire conquérante de Rome et à sa puissance de domination, se concentrent dans une période, le premier quart du $\mathrm{I}^{\mathrm{er}}$ s. ap. J.-C., qui, autant qu'on en puisse juger, fut assez calme pour la Craule Narbonnaise : entre la fin de la conquête des Alpes-Maritimes ${ }^{97}$, et les débuts du grand soulèvement de Sacrovir, qui ne devait d'ailleurs affecter qu'indirectement

95 Cf. (h. J.1:0x, op. cil., p. 199-200, pl. 137, l pefection de la hasilique consecutive à l'incendie de 1.4 as. J.-C.. Voir aussi, pour des décors analogues, M. P. Rossigxax, La decorazione archilettonica romana in P'arma, liome, 1973, p. 31, pl. III.

96 (i.-Ch. PICann, dans CR.1I, 1960, p. 13-16 ol dans Liarc a Orange, p. 80). Liare "date des environs de nolre eren. On notera que II. Kähler avait dejà releve la similitude entere les decors non figures de Cavailon el cenx de

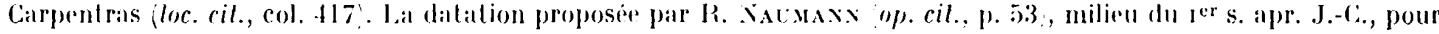
l'arc de Cavaillon, nous parail nettement trop basse.

97 Conquête marquée par la construction du Trophée de la Turbie en $7-6$ ar. J.- - C. C. en dernier lieu : le. Bк:o1т, Cimiez, la ville antique, Paris, 1977, p. 4 el s. 
la Gaule du sud, ces années paraissent prospères, et marquées par un intense développement urbain ${ }^{98}$. C'est d'ailleurs ce développement qui explique sans aucun doute l'apparition de beaucoup d'entre eux : les arcs de Glanum et d'Orange, par exemple, avaient pour fonction première de solenniser le passage de l'espace rural à l'espace urbain; comparables en cela aux ares romains de I)rusus sur la via Appia, de Portogallo sur la vie Flaminia ${ }^{99}$ ou encore à l'arc d'Aoste ${ }^{100}$, ils s'élevaient sur la ligne même du pomoerium ${ }^{101}$. Il serait donc aussi vain de leur chercher une fonction spécifiquement triomphale et guerrière, que de vouloir définir le rôle stratégique de certaines enceintes monumentales, dont P.-A. Février a montré qu'elles revêtaient, à la mème époque, une valeur essentiellement symbolique ${ }^{102}$.

Le problème qui demeure posé, dans ces conditions, est celui de la présence obsédante de ces figurations de barbares enchaînés, qui occupent tant de place à Carpentras, à Glanum, et sur les petits côtés de l'arc d'Orange; loin d'ofl'rir l'aspect anodin d'une image de convention, elles attirent le regard, non seulement par la place qu'elles occupent dans le programme iconographique, mais, quand il est encore possible de lire le détail des attitudes, par de saisissantes expressions de douleur et d'affliction. On n'explique peut-être pas totalement le phénomène en postulant, comme l'a fait naguère R. Bianchi Bandinelli, l'existence d'une puissante tradition hellénistique, et particulièrement pergaménienne, dans cette province occidentale ${ }^{103}$.

Mais nous abordons là un problème -- l'un des plus importants sans doute pour l'histoire des mentalités dans ces régions de l'Empire - dont le simple examen dépasserait largement le cadre de cette contribution.

Il resterait également à situer, chronologiquement, les très nombreux fragments d'arcs, retrouvés à Aix-en-Provence, Apt, Avignon, Narbonne, Vaison ou Vienne ${ }^{104}$. Si nous ne l'avons pas fait dans le présent article c'est qu'il nous a paru préférable d'attendre que soit terminé le recensement, commencé depuis peu, des fragments architecturaux hors-contexte des musées et des sites de Provence, afin de pouvoir travailler sur des séries complètes.

Pierre Gros.

98 (on connait la vilalité et la richesse revelees par " filanum III".

99 Cf. S. Stccent, L'arco dello di Porlogallo sulla via Flaminia, dans Bull. Com., 73, 1949-50, p. 101 et s. datation lrop tardive an ve s. ap. J.-C:. .

100 Voir A. I. Frotwalla .Jr, De la verilable signification des monuments romains quion appelle ares de Iriomphe. dans IRex, archeol., 1905, p. 205.

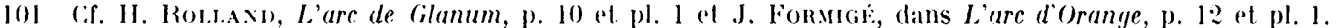

102 P.-A. Firnur, Enceinte el colonie (de Nìmes à lerone, Toulouse el Tipasa), dans Rev. El. Ligures, 35, 1969, p. 277 et s. - IIomm. à F. Benoil, III,

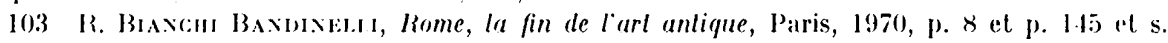

104 Cortains fragments importants de ces ares sont présentés dans le Recueil d'F. Espéraxirrev. Sur l'arc municipal de Vienne, cf. J. Fonmitit, dans Rev. archéol., 1951, p. 62 el s. fig. 6 el 8 .

N. B. - Ciliches de A. Chene, Centre Camille Jullian, fig. 4 et 20 a $2 x$; dessins de .1. Borely, Centre Camille Jullian, 